
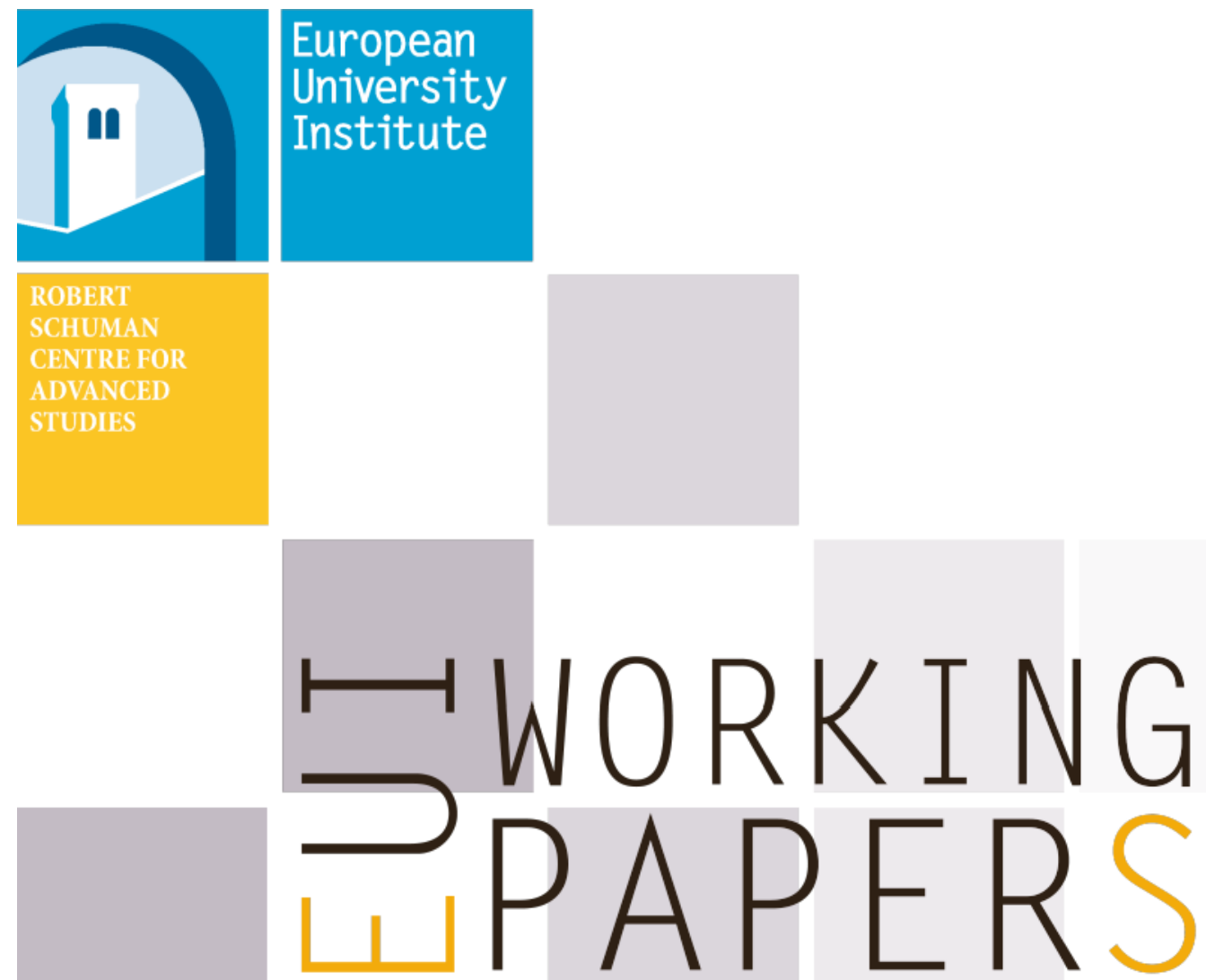

RSCAS 2017/20

Robert Schuman Centre for Advanced Studies Global Governance Programme-262

Re-estimating the effects of stricter standards on trade: endogeneity matters

Anirudh Shingal, Malte Ehrich and Liliana Foletti 

European University Institute

Robert Schuman Centre for Advanced Studies

Global Governance Programme

Re-estimating the effects of stricter standards on trade: endogeneity matters

Anirudh Shingal, Malte Ehrich and Liliana Foletti

EUI Working Paper RSCAS 2017/20 
This text may be downloaded only for personal research purposes. Additional reproduction for other purposes, whether in hard copies or electronically, requires the consent of the author(s), editor(s). If cited or quoted, reference should be made to the full name of the author(s), editor(s), the title, the working paper, or other series, the year and the publisher.

ISSN 1028-3625

(C) Anirudh Shingal, Malte Ehrich and Liliana Foletti, 2017

Printed in Italy, March 2017

European University Institute

Badia Fiesolana

I - 50014 San Domenico di Fiesole (FI)

Italy

www.eui.eu/RSCAS/Publications/

www.eui.eu

cadmus.eui.eu 


\section{Robert Schuman Centre for Advanced Studies}

The Robert Schuman Centre for Advanced Studies (RSCAS), created in 1992 and directed by Professor Brigid Laffan, aims to develop inter-disciplinary and comparative research and to promote work on the major issues facing the process of integration and European society.

The Centre is home to a large post-doctoral programme and hosts major research programmes and projects, and a range of working groups and ad hoc initiatives. The research agenda is organised around a set of core themes and is continuously evolving, reflecting the changing agenda of European integration and the expanding membership of the European Union.

Details of the research of the Centre can be found on:

http://www.eui.eu/RSCAS/Research/

Research publications take the form of Working Papers, Policy Papers, Policy Briefs, Distinguished Lectures, Research Project Reports and Books.

Most of these are also available on the RSCAS website:

http://www.eui.eu/RSCAS/Publications/

The EUI and the RSCAS are not responsible for the opinion expressed by the author(s).

\section{The Global Governance Programme at the EUI}

The Global Governance Programme is one of the flagship programmes of the Robert Schuman Centre for Advanced Studies at the European University Institute (EUI). It aims to: build a community of outstanding professors and scholars, produce high quality research and, engage with the world of practice through policy dialogue. At the Global Governance Programme, established and early career scholars research, write on and discuss, within and beyond academia, issues of global governance, focussing on four broad and interdisciplinary areas: European, Transnational and Global Governance; Global Economics; Europe in the World; and Cultural Pluralism.

The Programme also aims to contribute to the fostering of present and future generations of policy and decision makers through its unique executive training programme, the Academy of Global Governance, where theory and "real world" experience meet. At the Academy, executives, policy makers, diplomats, officials, private sector professionals and academics, have the opportunity to meet, share views and debate with leading academics, top-level officials, heads of international organisations and senior executives, on topical issues relating to governance.

For more information: http://globalgovernanceprogramme.eui.eu 



\title{
Re-estimating the effects of stricter standards on trade: endogeneity matters
}

\author{
Anirudh Shingal*, Malte Ehrich ${ }^{\dagger}$ and Liliana Foletti ${ }^{\ddagger}$
}

December 2016

\begin{abstract}
In their meta-analysis of estimates of the impact of technical barriers to trade, $\mathrm{Li}$ and Beghin (2012) note that studies using pesticides Maximum Residue Levels (MRLs) tend to find more trade impeding effects, but these studies do not directly address the problem of endogeneity in the standards-trade relationship. Using pesticides MRL data for 53 countries over 2005-2014, we re-examine the trade effects of stricter standards accounting fully for endogeneity using three-way fixed effects. We find that the direction of the estimated trade effects gets reversed and we discuss why endogeneity biases the estimates downwards. In another original contribution, we examine the standards-trade relationship by the direction of imposition of stricter standards for a large panel. Our results suggest that stricter standards facilitate trade, irrespective of who imposes them.
\end{abstract}

JEL classification: F13, F14, I18

Key words: Sanitary and Phytosanitary Measures, MRL Regulation, Relative Stringency, Endogeneity, Trade, Gravity

\footnotetext{
${ }^{*}$ Corresponding author; European University Institute, Florence and World Trade Institute, University of Bern (anirudh.shingal@eui.eu; anirudh.shingal@wti.org).

†University of Göttingen (malte.ehrich@agr.uni-goettingen.de)

$\ddagger$ University of Geneva (liliana.foletti@unige.ch)
} 


\section{Introduction}

The continual decline of tariffs through successive rounds of multilateral trade negotiations has increased the relative importance of non-tariff measures (NTMs). Sanitary and Phytosanitary (SPS) standards and technical barriers to trade (TBT) are two such NTMs, which though imposed for legitimate reasons such as alleviating information asymmetries, mitigating consumption risks and promoting environmental sustainability, can also be instruments of disguised protectionism.

Literature suggests that SPS and TBT measures can have both demand-enhancing and trade cost effects (Xiong and Beghin, 2014). Standards prescribe requirements for product characteristics, production processes and/or conformity assessment to address information problems, market failure externalities and societal concerns, which may assuage consumer concerns in importing countries. Standards can also convey positive information on product quality, again enhancing demand. Existing literature has documented the positive effects of standards on trade (Jaffee and Henson, 2004; Henson and Jaffee, 2008; Nimenya et al., 2012; Xiong and Beghin, 2013; Ishaq et al., 2016).

However, country-specific standards effectively create additional costs for foreign producers by forcing them to adjust their product and production process so as to meet individual national standards. Further costs emanate from the need for subsequent conformity assessment with these standards (for instance see Baldwin et al., 2000; Wilson and Otsuki, 2004; Chen et al., 2006; Chen and Mattoo, 2008) and inspection/testing at customs that lead to prolonged delivery times and even outright consignment rejection/entry denial (Xiong and Beghin, 2014). Other literature documenting the negative effects of standards on trade includes Otsuki et al., 2001; Disdier et al., 2008; Swinnen and Vandemoortele, 2011.

A commonly used standard in agricultural products restricts the maximum residue level (MRL) from pesticides. A pesticide residue is a tiny trace of pesticide that sometimes remains on the treated crop. An MRL is the maximum amount of residue legally permitted on food products. Once residues are demonstrated to be safe for consumption, MRLs are set by scientists, based on rigorous evaluation of each legally authorized pesticide. Countries choose the products they regulate, the pesticides they regulate for each product, as well as the MRL for a given product-pesticide pair.

The standards literature has studied the impact of MRL regulation on trade ${ }^{1}$. In their metaanalysis of estimates of the impact of TBT, Li and Beghin (2012) note that "studies using direct MRLs tend to find more trade impeding effects than other measures", but these studies

\footnotetext{
${ }^{1}$ The following section provides a review of the relevant literature.
} 
do not directly address the problem of endogeneity in the standards-trade relationship. This endogeneity could emanate from reverse causality, omitted variables and/or simultaneity. In this article, we therefore re-examine the effect of heterogeneity in $\mathrm{MRL}^{2}$ regulation on bilateral trade using the Homologa data ${ }^{3}$ on pesticide MRLs over 2005-2014 for 53 exporting and importing countries (details in Section 5). In doing so, we make two original empirical contributions to the impact assessment of standards literature.

To the best of our knowledge, we are the first to account fully for endogeneity in the standards-trade relationship using three-way fixed effects following the recent empirical trade literature (for instance see Baier and Bergstrand, 2007; Baier et al., 2014) and as also suggested by Li and Beghin (2012). We regard this to be a significant contribution because the recent standards literature confirms endogeneity in the MRLs-trade relationship (for instance see Beghin et al., 2013) and accounting for endogeneity like we do reverses the direction of the estimated trade effects.

In contrast, the existing impact assessment of standards literature either fails to account for the endogeneity in the standards-trade relationship (Jongwanich, 2009; Engler et al., 2012; Drogué and DeMaria, 2012; Winchester et al., 2012; Xiong and Beghin, 2013; Ishaq et al., 2016) or does so using instrumental variables on cross-sectional survey data (Hansen and Trifković, 2014; Melo et al., 2014). Xiong \& Beghin (2014) regard potential biases from endogeneity in their analyses to be limited while Ferro et al. (2015) do not include all appropriate fixed effects in their estimations.

Distinct from these approaches and following Baier et al. (2014), we estimate our empirical model in first differences including three-way fixed effects that fully account for endogeneity in the standards-trade relationship, besides controlling for sample selection and firm heterogeneity biases.

Secondly, we construct two indices of regulatory heterogeneity, which departing from existing literature, also examine the effect of heterogeneity on trade when the exporting country is bound to stricter regulation at home than in the destination market for a large sample of trading partners and years. As Xiong and Beghin (2013) point out, the direction of the

\footnotetext{
${ }^{2}$ We focus on MRLs to exploit the richness of our self-assembled database and because MRLs provide a continuous measure of relative stringency and are thus preferred in this literature (for instance see Melo et al., 2014) over the use of count or frequency measures.

${ }^{3}$ Drogué and DeMaria (2012), Xiong and Beghin (2014) and Ferro et al. (2015) also use the same base data obtained from Agrobase-Logigram, a private company that maintains Homologa, the Gobal Crop Protection Database, though there are significant differences in the underlying sample in each case. For instance Drogué and DeMaria (2012) only focus on apples and pears, while Xiong and Beghin (2014) only consider a cross-section of the Homologa data for the year 2008. We also have a longer panel than in Ferro et al. (2015).
} 
own-export effect of a domestic standard depends on whether the domestic industry has a comparative advantage in meeting regulations and on whether consumer preferences in the importing country are pro-food safety.

However, studies analyzing the effect of SPS/TBT measures on trade either assume no effect from regulatory dissimilarity when the exporter is stricter (Burnquist et al., 2011; Xiong and Beghin, 2014; Ferro et al., 2015) or that all regulation heterogeneity leads to compliance costs for the exporter in the destination market, whether or not regulations are stricter in the exporter market (Achterbosch et al., 2009; Drogué and DeMaria, 2012; Winchester et al., 2012). The sole exception is Xiong and Beghin (2013) who study the effect of both relative importer and exporter stringency in the same estimating equation, but they only study effects on US and Canadian trade for one year (2010).

Our results for a larger set of trading partners and years suggest that once endogeneity in the standards-trade relationship is fully accounted for, stricter standards facilitate trade irrespective of who imposes them, thereby underlining the greater demand-enhancing effect of more stringent regulation. This result is in contrast to most other findings on the trade effects of pesticides MRLs in this literature.

The rest of the article is structured as follows. The following section reviews some of the relevant literature. Section 3 discusses why endogeneity may arise in the standards-trade relationship and why endogeneity-induced biases may underestimate the trade effects. Section 4 describes the measures of relative MRL stringency we construct to examine trade effects by source of heterogeneity. Section 5 looks at the data while Section 6 presents the empirical methodology used to estimate the trade effects of stricter MRLs. Theresults are discussed in Section 7 before concluding in Section 8.

\section{Literature review}

Most work on the link between harmonization of standards and trade is empirical in nature and theoretical literature on this subject remains scant. Ganslandt and Markusen (2001) have modeled TBTs formally (though not their liberalization). Baldwin et al. (2000) and Chen and Mattoo (2008) have modeled both TBTs and their harmonization, cautioning against the discriminatory effects that the latter may entail. More recently, Xiong and Beghin (2014) have disentangled the demand-enhancing and trade cost effects of MRL regulation in a generalized gravity model setting. In what follows, we provide a select review of empirical studies assessing the trade effects of pesticides MRLs. In sum, this empirical literature finds 
regulatory harmonization of MRLs to be trade-facilitating and differences in MRL regulation to be trade-restrictive ${ }^{4}$.

Achterbosch et al. (2009) studied the impact of differences in pesticide MRLs on Chilean fruits exports to the EU15 over 1996-2007 and found a 5\% reduction in the EU's regulatory tolerance levels for MRLs to lead to a $14.8 \%$ decline in export volumes, with grapes being twice as sensitive as the other fruits. Melo et al. (2014) examined regulatory harmonization in a range of SPS and quality (SPSQ) measures (including MRLs) on Chilean fresh fruit exports in 16 destination markets based on the number of regulations and exporters perception of the stringency of SPSQ measures over 2005-09. They find a rise in stringency to have substantial negative effects on export volumes, with different dimensions of SPSQ measures having different effects on trade.

In different ways, papers similar to ours are Winchester et al. (2012), Drogué and DeMaria (2012), Xiong and Beghin (2013), Xiong and Beghin (2014) and Ferro et al. (2015). However, in addition to differences in sample and measures of the regulatory heterogeneity index used, with the exception of Xiong and Beghin (2013), none of these papers examines the trade effects of more stringent standards by the direction of their imposition.

Winchester et al. (2012) study the impact of regulatory heterogeneity on the EU's agri-food export intensity in the year 2009-10 by using the NTM-Impact database that was assembled under a European research framework programme. Their results indicate that differences in most regulations weakly reduce trade, but that stricter MRLs for plant products in one country relative to others reduces exports to that country.

Drogué and DeMaria (2012) construct an index of regulatory heterogeneity in MRLs following that in Vigani et al. (2010) to examine its effect on bilateral export intensity of fresh and processed apples and pears among 40 trading partners over 2000-09. They also find regulatory differences to hinder trade.

Xiong and Beghin (2013) use MRL data from the US Department of Agriculture to construct heterogeneity indices relative to Codex MRLs (following Li and Beghin, 2014) and examine the effects of relative importer and exporter stringency for US and Canadian trade in 2010. They find US exports to be adversely affected by relative importer stringency but Canadian exports to benefit from more stringent MRL regulation, irrespective of the source of such regulation. However, regulatory heterogeneity does not affect US or Canadian imports in their results.

\footnotetext{
${ }^{4}$ One recent exception to this is Ishaq et al. (2016), who use the Li \& Beghin (2014) stringency indices to examine the effect of stricter (than Codex) importing country standards on Chinese exports over 2012-2013 and find this effect to be positive.
} 
Xiong and Beghin (2014) disentangle the cost-escalating and demand-enhancing effects of MRLs in 20 OECD importing countries in 2007-08 and 2011-12 at both margins of trade using the Li and Beghin (2014) stringency index that measures MRL restrictiveness relative to Codex standards. They find MRLs to jointly enhance import demand and hinder foreign export supply.

Ferro et al. (2015) use the same base data on pesticide MRLs as us to study the effects of standards restrictiveness on agri-exports in importing countries over 2006-11. The authors find more restrictive standards in the destination market to adversely affect the probability of exporting, but unlike us, they do not consider the case where the exporting country has more stringent regulation, assuming this to have no impact on importing country decisions. With the exception of Xiong and Beghin (2013), all studies cited in this section conclude that relative MRL stringency hinders trade. But none of these studies accounts for endogeneity in the standards-trade relationship as we do. As we show below, a significant outcome of fully accounting for endogeneity like we do is a reversal in the direction of the estimated trade effects. Thus contrary to most studies reviewed here we find stricter standards to facilitate trade, irrespective of the direction of their imposition.

\section{Endogeneity in the standards-trade relationship}

The level and stringency of MRLs may not depend solely on scientific and health concerns regarding the pesticide but also on economic and political determinants thereby making the standards-trade relationship endogeneous. For instance, Li (2012) found tariffs and MRL stringency to be jointly determined alluding to the role of political decision-making in the design or implementation of MRL policies. In fact, since one of the determinants of MRLs is consumption, it is possible that countries set stricter standards on products that are more consumed and imported. Consistent with this argument, Beghin et al. (2013) show that tariffs and MRLs are used as substitutes by policy-makers.

Analogously, exporting countries may deploy more stringent standards for products that are more likely to be exported, especially in cases where exporting firms have a comparative advantage in meeting such regulation and where such exports are destined for more pro-food safety markets (for instance see Xiong and Beghin, 2013). As the authors point out, two rationales justify this choice: one, meeting more stringent regulation at home saves exporters rejections at the border of the destination market (an extensive margin effect) and two, lower tolerance levels at home enhance exporter reputation abroad where food-safety may pay off in terms of higher premium or repeated purchase (an intensive margin effect). 
Econometrically, if any of the explanatory variables in the baseline estimating equation (see Section6 for details) are correlated with the error term, that variable is considered econometrically "endogenous" and ordinary least squares (OLS) may yield biased and inconsistent coefficient estimates. This endogeneity could emanate both from omitted variables and simultaneity (Wooldridge, 2010).

\subsection{Omitted variable bias}

Beghin et al. (2013) show that MRL stringency is positively correlated with income per capita and population of the importing country. Both these factors are also important determinants of bilateral trade, suggesting that the standards-trade relationship is not exogenous. Thus, in terms of observable economic characteristics, countries with stricter standards also tend to have the economic characteristics associated with more trade.

However, the error term may also include unobservable factors that tend to reduce bilateral trade and remain unaccounted for by standard gravity covariates but may be correlated with the decision to impose a more stringent standard. One likely omitted variable in the context of this study is consumer preferences. If importing country consumers are risk-averse, then they are less likely to consume imported products (causing the error term to be negative). Such consumers are also more likely to lobby for more stringent regulation, yielding a positive correlation between consumer preferences and stricter standards, though the error term and consumer preferences may be negatively correlated. This suggests that relative importer stringency and the error term would be negatively correlated, and the coefficient of relative importer stringency will tend to be underestimated.

Similarly if exporting country consumers are more pro-food safety, then most domestic production would cater to these domestic preferences (causing the error term to be negative). Such consumers are also more likely to lobby for more stringent regulation, yielding a positive correlation between consumer preferences and stricter standards, though the error term and consumer preferences may be negatively correlated. This suggests that relative exporter stringency and the error term would be negatively correlated, and the coefficient of relative exporter stringency will also tend to be underestimated.

\subsection{Simultaneity bias}

Holding standard gravity covariates constant, two countries that trade more than their "natural" level as predicted by a typical gravity equation, may be induced to "lower" or harmonize 
standards, for instance in recognition of their long-established trading relationship. This would cause a negative simultaneity bias in the estimated relative stringency coefficients. An illustration of this is provided in existing literature via the "protection for sale" argument (Grossman and Helpman, 1994) wherein import penetration and protectionism are inversely related. More recently, Beghin et al. (2013) also show that countries adopt less stringent MRLs in sectors where domestic producers are more competitive in the world market.

In sum, endogeneity in the standards-trade relationship clearly matters and the underlying simultaneity and omitted variable biases are likely to underestimate the coefficients of the relative stringency indices. In fact, Li and Beghin (2012) also point out that both Trefler (1993) and Lee and Swagel (1997) have shown that endogeneity could lead to an underestimation of NTMs' trade effects. Fully accounting for endogeneity-induced biases econometrically is therefore likely to be trade enhancing.

\section{The source of heterogeneity matters}

With the exception of Xiong and Beghin (2013), studies analyzing the trade effect of standards either assume no effect from regulatory dissimilarity when the exporter is stricter (Burnquist et al., 2011; Xiong and Beghin, 2014; Ferro et al., 2015) or that all regulation heterogeneity leads to compliance costs for the exporter in the destination market, whether or not regulations are stricter in the exporter market (Achterbosch et al., 2009; Drogué and DeMaria, 2012; Winchester et al., 2012).

These assumptions are clear from the quotations below:

"... if the MRL level is stricter in the exporter country than in the importer country, then the latter's MRL standard should have no effect on its imports from the exporter country." (Ferro et al., 2015, p.74)

“...exporters who have been subject to tougher MRLs in their domestic markets...are less likely to experience trade disruption..." (Xiong and Beghin, 2014, p.1193)

One important motivation for our research is to empirically examine the hypotheses inherent in these quotes.

To do so, we construct a modified version of the Achterbosch et al. (2009) heterogeneity index by taking the absolute value of the difference in MRL regulation between countries in a trading dyad and normalizing it by the sum of the levels of MRL regulation in that dyad ${ }^{5}$. Formally, we have:

\footnotetext{
${ }^{5}$ Note that, unlike the Li and Beghin (2014) index that measures MRL stringency of the importer relative
} 


$$
r_{i j p k t}=\frac{a b s\left(M R L_{i p k t}-M R L_{j p k t}\right)}{M R L_{i p k t}+M R L_{j p k t}}
$$

where $M R L_{i p k t}$ is the maximum residue level of pesticide $k$ allowed by the exporter $i$ to remain on product $p$ and $M R L_{j p k t}$ is the maximum residue level of pesticide $k$ allowed by the importer $j$ to remain on product $p^{6}$. Thus, the index, $r$, measures the degree of heterogeneity of MRL regulation between exporter $i$ and importer $j$, regarding the maximum residue level of pesticide $k$ allowed to remain on product $p$. The value of the index ranges between 0 and 1 , where $r=0$ indicates that for the same pesticide and crop, the importer and exporter have equal MRLs and there is therefore no heterogeneity ${ }^{7}$.

To examine the assumptions inherent in the quotations mentioned at the beginning of this section, namely that regulatory heterogeneity affects trade only when the importer is stricter, we separate ${ }^{8}$ the heterogeneity index into two sub-indices: $s^{m}$ and $s^{x}$, the former corresponding to heterogeneity emanating from cases in which the importer has more stringent regulation, and the latter to cases in which the exporter is equally or more stringent ${ }^{9}$.

$$
s_{i j p k t}^{m}= \begin{cases}\frac{a b s\left(M R L_{i p k t}-M R L_{j p k t}\right)}{M R L_{i p k t}+M R L_{j p k t}} & \text { if } M R L_{i p k t}>M R L_{j p k t} \\ 0 & \text { otherwise }\end{cases}
$$

to the Codex and is convex in protectionism, the Achterbosch et al. (2009) index (as well as the Winchester et al. (2012) index that we use in our sensitivity analyses) simply linearizes the difference in MRL regulation within a dyad. However, convexity in protectionism is required in an index that is constructed relative to the Codex, which is an international standard, not in an index which measures stringency relative to the standard set by another country.

${ }^{6}$ Thus, the $M R L_{i p k t}$ and $M R L_{j p k t}$ are non-negative variables, that are theoretically unbounded but bounded from above in practice.

${ }^{7}$ We use the modified Achterbosch et al. (2009) index over other measures of regulatory heterogeneity used in the literature as this index measures MRL stringency relative to the MRL set by another trading partner in our country sample and not relative to the Codex or another international standard $a$ la $\mathrm{Li}$ and Beghin (2014). In that sense, the Achterbosch et al. (2009) index is dyadic and more pertinent to our research question. The similarity index used by Drogué and DeMaria (2012) only captures the linear relationship between the two MRL regulations and does not consider differences in levels: two countries might have perfectly collinear regulation but at different levels, thus having a similarity index of 0 (very similar) and yet be very different in terms of stringency. This said, in our sensitivity analyses, we also find our empirical findings to be robust to the use of the Winchester et al. (2012) index.

${ }^{8} \mathrm{We}$ are aware of the problems associated with dichotomizing the expanatory variable and therefore examine the robustness of our "endogeneity" findings to the dichotomization of the relative MRL stringency index below (see Section 7.3.2).

${ }^{9}$ In another robustness check, we experimented with a stronger definition of relative exporter stringency, i.e. $M R L_{i p k t}<M R L_{j p k t}$. Our empirical findings were found to be robust to this change in definition. 


$$
s_{i j p k t}^{x}= \begin{cases}\frac{a b s\left(M R L_{i p k t}-M R L_{j p k t}\right)}{M R L_{i p k t}+M R L_{j p k t}} & \text { if } M R L_{i p k t} \leq M R L_{j p k t} \\ 0 & \text { otherwise }\end{cases}
$$

In contrast to the existing literature, we thus consider the effects of regulatory heterogeneity on trade by source of such heterogeneity. This distinguishes us from the approach of simply ignoring heterogeneity when the exporter is stricter (Burnquist et al., 2011; Xiong and Beghin, 2014; Ferro et al., 2015) and from the approach that heterogeneity always imposes compliance costs for the exporter in the importing country (Achterbosch et al., 2009; Drogué and DeMaria, 2012; Winchester et al., 2012).

Following standard practice in this literature (for instance see Li and Beghin, 2014), we construct aggregate indices for each product averaging over the number of pesticides used per product ${ }^{10}$. Thus we have:

$$
\begin{aligned}
& S_{i j p t}^{M}=\frac{1}{K} \sum_{k=1}^{K} s_{i j p k t}^{m} \\
& S_{i j p t}^{X}=\frac{1}{K} \sum_{k=1}^{K} s_{i j p k t}^{x}
\end{aligned}
$$

where $K$ is the total number of pesticides for which there is an MRL on product p.

Following the standards literature (for instance see Xiong and Beghin, 2014), more stringent MRL regulation is likely to have both a demand-enhancing effect in the importing country and a trade-cost effect on export supply; as such, the net effect on trade and the coefficients of the $S_{i j p t}^{M}$ and $S_{i j p t}^{X}$ indices can be either positive or negative depending on which effect prevails, so it would be useful to examine this for our data.

If we consider the index $S_{i j p t}^{M}$, a strong negative effect at the extensive margin would suggest that having dissimilar MRL regulations between countries is a fixed cost that producers have to overcome before being able to export towards a more stringent destination. The same effect at the intensive margin may suggest that the costs of complying with different

\footnotetext{
${ }^{10}$ The number of pesticides regulated is found to vary by product. For instance, the US has 107 pesticide MRLs for apples but only 7 pesticide MRLs for coconut (Li and Beghin, 2014). By averaging the sum of the relative stringency index of each pesticide by the total number of pesticides, we make the indices invariant to regulation intensity a la $\mathrm{Li}$ and Beghin, 2014. The use of the simple average thus avoids assigning higher values to certain products simply because a greater number of pesticides are commonly applied to those products.
} 
MRL regulations is variable and increases with the value of exports. Literature suggests that relative importer stringency may affect both fixed and variable costs (for instance see Ferro et al., 2015 and Xiong and Beghin, 2014, respectively).

In considering the $S_{i j p t}^{X}$ index, a positive trade effect of stricter standards could be due to an increased demand in the destination market thanks to the positive signaling effect of more stringent regulation, or due to more efficient and productive techniques used in markets where regulations are stricter (for instance see Blind and Jungmittag, 2005; Xiong and Beghin, 2013).

However, meeting stricter standards also involves higher costs which may get passed-through to consumers as higher prices. This said, the trade cost effects of more stringent domestic regulation are likely to be low if domestic industry has a comparative advantage in meeting such regulation (Xiong and Beghin, 2013). Moreover, especially in the case of pesticide MRLs, consumer preferences in the importing country may be less or more pro-food safety and this would also have a bearing on which effect would prevail in the end.

For all of these reasons, the net effect of stricter standards on trade can be either positive or negative and we therefore consider it useful to examine the potential asymmetric impact of regulatory heterogeneity not just on exports destined for more stringent markets but even on exports coming from more stringent countries for a larger panel of trading partners and years than in Xiong and Beghin (2013).

Finally, we would like to point out a few cases in the construction of the heterogeneity indices. Not all countries set MRLs for the same pesticide/crop combination; it can therefore be the case that the importer country sets an MRL for a $k, p$ pair for which the exporting country has not set a limit and we would therefore have to drop this observation as no comparison is possible. To minimize this from happening, and without imputing values arbitrarily, we resort to default $M R L$ values $^{11}$. Some countries set default MRLs for any $k, p$ combination that is not explicitly cited in their MRL regulation, such as the EU that sets an MRL of $0.01 \mathrm{mg} / \mathrm{kg}$ for any pesticide on any crop that is not listed in the European Commission Regulation No 396/2005.

Table 1 summarizes the pertinent default MRL cases. Thus, in cases where one of the partner countries was missing the MRL, we resort to the missing country's default value (if any) to compute the heterogeneity index. In cases where there is no default MRL in place as well, we replace the missing MRL with the sample's highest MRL following Drogué et al. (2012) and Ferro et al. (2015).

\footnotetext{
${ }^{11}$ Drogué and DeMaria (2012) and Xiong and Beghin (2014) also resort to default values, and to the best of our knowledge they are the only ones doing so apart from us.
} 
In the empirical analyses that follow, we examine the sensitivity of our results both to the use of default MRL values and to replacements by the sample maxima by considering three different samples: Sample 1 (missing MRLs not replaced); Sample 2 (missing MRLs only replaced by default MRLs) and Sample 3 - "the full sample" (missing MRLs in Sample 2 replaced by sample maxima).

\section{$<$ Insert Table 1 here $>$}

\section{Data}

We use data on MRL regulation covering the period between 2005 and 2014 in the following 53 importing and exporting countries: Argentina, Australia, Brazil, Canada, Chile, China, Colombia, Egypt, India, Israel, Japan, Korea, Mexico, Malaysia, Norway, New Zealand, Russia, Singapore, South Africa, Switzerland, Thailand, Turkey, Ukraine, USA and the EU28 members. The data on MRL regulation were acquired from Agrobase-Logigram, a private company that maintains Homologa, the Gobal Crop Protection Database, using information from pertinent national ministries and legal publications.

However, the richness of the data received from Homologa that covers 2638 products ${ }^{12}$ could not be fully exploited because a large amount of crops are too specific compared to the Harmonized System (HS) 6-level data. To enable an empirical trade analysis of these MRLs, it becomes impossible to use all the Homologa data since that would introduce MRL variation within the HS code that cannot be matched by trade variables. We therefore selected products that matched perfectly. These 31 products are reported in Table 8.

The analyses are conducted at the disaggregated HS-six-digit product level, focusing on trade in HS Chapters 7 and 8 over 2005-14. These HS Chapters correspond to the agriculture fruit and vegetables sectors where pesticide MRLs are relevant. Fruits and vegetables in particular are interesting sectors to analyze because these are rejected more often than other products like meat or dairy products. For instance, the EU reports 2621 rejections by a member state of the EU from 2008 to 2015 with an increasing trend (Fiankor et al., 2016).

Export data come from the UN Comtrade database in current USD. Data on (simple average) applied tariffs are sourced from the International Trade Center. The bilateral trade cost

\footnotetext{
${ }^{12}$ Including subcategories of products at various levels of aggregation.
} 
variables are taken from CEPII (Head et al., 2010) and data for PTA-membership come from De Sousa ${ }^{13}$.

Descriptive statistics are provided in Table 2. The full, strongly balanced, sample has 811,850 observations. Trade values are positive for about $25 \%$ of these. Correlation between the restrictiveness indices $S_{i j p t}^{M}$ and $S_{i j p t}^{X}$ were found to vary beteween -0.04 (Sample 2) and -0.13 (Samples 1 and 3), which obviates concerns about multicollinearity in estimation and statistically supports our strategy to distinguish between relative importer and exporter stringencies in our estimating equations. The original dataset without any MRL replacements (Sample 1) has 580,154 observations; the sample size goes up to 731,634 with missing MRLs replaced with default values (Sample 2), and further to 811,850 with sample maxima used to replace missing MRLs in cases which did not even report default MRLs (Sample 3).

\section{$<$ Insert Table 2 here $>$}

At the product level, the mean values of $S_{i j p t}^{M}$ and $S_{i j p t}^{X}$ by country averaged over 2005-2014 for Sample 1 (missing MRLs not replaced) are shown in Figures 1 and 2, respectively. Figure 1 shows that Ukraine, Brazil, Germany, South Africa, Czech Republic and Austria are the strictest importers (on average) relative to their exporters for our product and year coverage. In general, developed countries exhibit larger magnitudes of relative importer stringency compared to the developing world (Vietnam, India, China, Malaysia) in our product-level data averaged over 2005-2014. The ranking of countries by relative exporter stringency is also similar (see Figure 2). Most European countries are ranked in the middle of the distributions.

\section{$<$ Insert Figures 1 and 2 here $>$}

Figure 3 shows the average number of pesticides regulated per product in each country at two points in time (2005 and 2014). Figure 3 reveals that developed countries (Germany, Austria, Japan) regulate a much larger number of pesticides per product and even though there have been significant changes within the overall distribution, the broad picture is fairly constant over time, with developing countries regulating far fewer pesticides per product. Figure 4, which shows the average number of products for which MRLs are set in each country (again across 2005, 2014), reveals the same pattern. Developed countries like Canada and the US are also far more active in setting pesticides standards.

\section{$<$ Insert Figures 3 and 4 here $>$}

\footnotetext{
${ }^{13}$ http://jdesousa.univ.free.fr/data.htm
} 


\section{Empirical model}

Our empirical analysis is conducted in the framework of the gravity model as laid down by Anderson (1979). Following Anderson and van Wincoop (2004), the value of trade between country $i$ and country $j$ of product $p$ at time $t$ can be written as follows:

$$
T_{i j t}^{p}=\frac{E_{j t}^{p} Y_{i t}^{p}}{Y_{t}^{p}}\left(\frac{\phi_{i j t}^{p}}{P_{i t}^{p} \Pi_{j t}^{p}}\right)^{\left(1-\sigma^{p}\right)}
$$

where $T_{i j t}^{p}$ denotes the value of trade (average of imports and exports) of product $p$ between country $i$ and $j$ at time $t, E_{j}^{p}$ is the expenditure in the destination country $j$ of product $p, Y_{i}^{p}$ denotes the total sales of exporter $i$ towards all destinations, $Y^{p}$ is the total world output of product $p, \phi_{i j}$ are the bilateral trade costs and $\sigma^{p}$ is the elasticity of substitution across products. $P_{i t}^{p}$ and $\Pi_{j t}^{p}$ are the Multilateral Resistance Terms (MRTs) i.e. the outward and inward relative resistance of a country's trade towards all destinations and from all origins ${ }^{14}$. Since these terms are difficult to construct directly as national price indices are needed, applications of the gravity model resort to using dummy variables to control for them instead. At the sectoral level, time-varying importer-product and exporter-product fixed effects control for the MRTs in a panel setting (Anderson and Yotov, 2012).

Bilateral trade costs in $\phi_{i j p t}^{15}$ arise from different sources such as import tariffs, $\tau_{i j p t}$; geographical distance between trading partners, $\ln \left(\right.$ Dist $\left._{i j}\right)$; cultural distance proxied by dummy variables identifying whether the trading partners share a common border, Contigij, had a colonial relationship, Colony $y_{i j}$, and share a common language, ComLang ${ }_{i j}$; and in the context of this study, differences in MRL regulation, $S_{i j p t}^{M}$ and $S_{i j p t}^{X}$.

These variables enter $\phi_{i j p t}$ as follows:

$\phi^{1-\sigma}{ }_{i j p t}=\exp \left(\beta_{1} S_{i j p t}^{M}+\beta_{2} S_{i j p t}^{X}+\beta_{3} \ln \left(1+\tau_{i j p t}\right)+\beta_{4} \ln \left(\right.\right.$ Dist $\left._{i j}\right)+\beta_{5}$ Contig $_{i j}+\beta_{6}$ ComLang $\left._{i j}\right)$

Substituting (7) into (6), adding an error term, and taking the log of the resulting multiplicative model, yields the following estimating equation:

\footnotetext{
${ }^{14}$ The MRTs are derived theoretically in Anderson and Van Wincoop (2003).

${ }^{15}$ The notation, regarding the subscripts, is slightly modified to accommodate the product dimension, p.
} 
$\ln \left(T_{i j p t}\right)=\beta_{1} S_{i j p t}^{M}+\beta_{2} S_{i j p t}^{X}+\beta_{3} \ln \left(1+\tau_{i j p t}\right)+\delta_{1} \ln \left(\right.$ Dist $\left._{i j}\right)+\delta_{2}$ Contig $_{i j}+\delta_{3}$ ComLang $_{i j}+\mu_{i p t}+\gamma_{j p t}+\epsilon_{i j p t}$

where $\mu_{i p t}$ and $\gamma_{j p t}$ are the time-varying exporter-product and importer-product fixed effects that proxy the MRTs and $\varepsilon_{i j p t}$ is the error term. Note that, consistent with Baldwin and Taglioni (2006), the dependent variable is constructed as the average of the log of imports and exports.

\subsection{Estimation issues}

Two stylized features of trade data that challenge the estimation of structural gravity models are sample selection and heteroskedasticity (Xiong and Chen, 2014). As seen in Table 2, $T_{i j p t}$ equals zero in at least $75 \%$ of all observations across the three samples. Sample selection is therefore clearly a concern in our data. One possible estimation strategy is the two-stage Heckman as implemented by Helpman et al. (2008).

The sample selection bias - coefficient of the inverse mills ratio calculated from the selection equation of the two-step Heckman - was found to be statistically significant in our estimation results. Following Xiong and Chen (2014), this negated the use of alternative estimation strategies such as the Poisson Pseudo-Maximum Likelihood (Silva and Tenreyro, 2006), even though the latter addresses problems associated with heteroskedastic errors by characterizing trade multiplicatively in levels as opposed to log-linearly ${ }^{16}$.

However, for the reasons discussed in Section 4, an arguably bigger estimation challenge in this study is the endogeneity in the standards-trade relationship. One possible estimation strategy which could address all three issues - sample selection, heteroskedasticity and endogeneity - is the Two-Step Method of Moments (TS-MM) estimator ${ }^{17}$ proposed by Xiong and Chen (2014), where the outcome equation is estimated using Generalized Method of Moments (GMM) to account for endogeneity in the standards-trade relationship. However, the use of GMM requires the fixed effects to be time-invariant, which is not true in our case $^{18}$.

\footnotetext{
${ }^{16}$ Moreover, PPML estimation with three high-dimensional fixed effects was a computational challenge despite using work-around strategies suggested by Silva and Tenreyro (2010).

${ }^{17}$ The first step of the TS-MM is identical to the Heckman proposed by Helpman et al. (2008); however, the second stage characterizes trade in levels to be estimated on the sample of positive exports using the Method of Moments (for details see Xiong and Chen, 2014).

${ }^{18}$ Moreover, as Rodman (2009) points out, when the dependent variable is close to a random-walk then the Difference GMM performs poorly while the validity of the System GMM depends on the assumption that
} 
We therefore decided to account for endogeneity using three-way fixed effects in line with recent empirical trade literature, in particular Baier et al. (2014) and as also suggested by Li and Beghin (2012). This also obviates the need for finding valid instruments for endogenous variables, which was an additional challenge in the context of this study.

Baier et al. (2014) examine the effect of trade agreements on bilateral goods trade accounting for the likely self-selection of trading partners into such agreements. To do so, they propose fixed effects (FE), first difference (FD) and random growth first difference (RGFD) models, that would entail the following empirical specifications in the context of our equation (8):

$$
F E: \quad \ln T_{i j p t}=\beta_{1} S_{i j p t}^{M}+\beta_{2} S_{i j p t}^{X}+\beta_{3} \ln \left(1+\tau_{i j p t}\right)+\mu_{i p t}+\gamma_{j p t}+\eta_{i j}+\epsilon_{i j p t}
$$

$$
F D: \quad d . \ln T_{i j p t}=\beta_{1}\left(d . S_{i j p t}^{M}\right)+\beta_{2}\left(d . S_{i j p t}^{X}\right)+\beta_{3}\left(d . \ln \left(1+\tau_{i j p t}\right)\right)+\mu_{d . i p t}+\gamma_{d . j p t}+\epsilon_{d . i j p t}
$$

$R G F D: \quad d . \ln T_{i j p t}=\beta_{1}\left(d . S_{i j p t}^{M}\right)+\beta_{2}\left(d . S_{i j p t}^{X}\right)+\beta_{3}\left(d . \ln \left(1+\tau_{i j p t}\right)\right)+\mu_{d . i p t}+\gamma_{d . j p t}+\eta_{i j}+\epsilon_{d . i j p t}$

where in addition to the variables already described above, $\eta_{i j}$ are pairwise bilateral fixed effects and $d$ is the difference operator ${ }^{19}$.

Note that the use of importer-product-time, exporter-product-time and dyadic fixed effects in these models fully accounts for endogeneity in the standards-trade relationship. The use of time-varying importer-product and exporter-product fixed effects accounts for most of the omitted variables that lead to endogeneity in the standards-trade relationship (for e.g. consumer preferences discussed in Section 3.1). Moreover, any change in regulation may also be motivated by bilateral factors (as discussed in Section 3.2), which necessiates the use of dyadic fixed effects to additionally control for all such possible bilateral factors. The use of all three fixed effects together, hitherto ignored in the existing standards-trade literature, thus fully accounts for endogeneity in the standards-trade relationship and reverses the direction of the estimated trade effects, as we shall see in the next section.

the errors are not serially correlated. Our dependent variable was found to be close to a unit root process and our errors were strongly correlated over time; both findings thus further pointed against the use of the GMM.

${ }^{19}$ Baier et al. (2014) used differencing over five years as they had a panel over 1962-2000 but their results were robust to first differencing their data. While we use first differences in estimation, our results from the RGFD models were robust to differencing the data over two, three and four years. These results are available upon request. 


\subsubsection{RGFD model as the preferred estimation}

Following Wooldridge (2010, Ch. 10), Baier et al. (2014) suggest that when t $>2$, the FE estimator is more efficient than the FD estimator if the errors from estimating equation (9) are serially uncorrelated while the FD estimator is more efficient than the FE estimator if the error term follows a random walk. In general, FD estimates are more efficient than FE estimates if the errors from the FE model are highly serially correlated and the dependent variable follows a unit root process.

In our $\mathrm{t}>2$ panel structure, we found the estimated error term from equation (9) to be highly serially correlated and our dependent variable to be close to a unit root process. This suggested that the FD would be more efficient than the FE model.

Compared to the FD model, the additional use of dyadic fixed effects gives the RGFD model the added advantage of controlling for changes over time in pairwise unobservables, such as the experience acquired in exporting to a particular market, that are unrelated to stricter standards. We therefore decided to estimate equation (8) using the RGFD model proposed by Baier et al. (2014). This estimation strategy fully accounts for endogeneity in the standards-trade relationship. It also corrects for biases emanating from sample selection and firm heterogeneity by accounting for fluctuations across country pairs and over time in the latent variable $z_{i j p t}{ }^{20}$ that reflects the ratio of variable export profits to fixed export costs for the most productive firm (for details see Baier et al., 2014, p.346).

\subsubsection{Two-stage Heckman to replicate existing results in the literature}

For the sake of replicating estimation strategies and some of the findings in recent papers using variants of the same dataset as ours (for instance Xiong and Beghin, 2014; Ferro et al. 2015), we begin by estimating equation (8) using the two-step Heckman without fully accounting for endogeneity. Given the exclusion restriction issue in Heckman-type estimations emphasized in the heterogeneous firm trade literature (for instance see Head and Mayer, 2013), we closely follow Helpman et al. (2008) in our estimation strategy.

Following Xiong and Beghin (2014), we use an indicator variable for common religion interacted with HS-4 chapter fixed effects as the exclusion variable ${ }^{21}, E V_{i j p t}$, to allow for

\footnotetext{
${ }^{20}$ Helpman et al. (2008) show that accounting for $z_{i j p t}$ accounts for both the Heckman selection bias (the inverse mills ratio is a monotonic function of $z_{i j p t}$ ) and the firm heterogeneity bias (the control for this is a function of $z_{i j p t}$ and the inverse mills ratio (which in-turn is a function of $z_{i j p t}$ )).

${ }^{21}$ Only the common religion variable was found to satisfy this requirement in our data set.
} 
heterogeneity across sectors in the self-selection process ${ }^{22}$. We use the predicted probabilities, $\hat{\rho_{i j p t}}$, from the selection equation to construct the inverse mills ratio ${ }^{23}, \eta_{i j p t}$, which is included in the outcome equation to control for the selection bias. Following (Helpman et al., 2008), we also control for biases emanating from firm heterogeneity in the outcome equation by including a cube polynomial of $z_{i j p t}$ where $z_{i j p t}=\eta_{i j p t}+\rho_{i j p t}{ }^{24}$.

Given concerns associated with incidental parameters (Lancaster, 2000) in the use of fixed effects in non-linear estimations, we estimated the selection equation using the Linear Probability model (LPM).

Finally, to accomodate the very large number of fixed effects that we needed to include to control for MRTs in both the Heckman and the RGFD models, we resorted to using the 2WFE estimator proposed and $\operatorname{coded}^{25}$ by Guimarães and Portugal (2010).

\section{$7 \quad$ Results and analysis}

\subsection{Heckman estimates: replicating results in existing literature}

Table 3 reports the results of the Heckman two-step estimations of our baseline specification on all three samples but without fully accounting for endogeneity in the estimating equation using three-way fixed effects. All estimations include only time-varying importer-product and exporter-product fixed effects, with the product defined at the HS-4 product level to reduce the dimension of the econometric specification and to obviate concerns about fixed effects constructed at the HS-6 product level being collinear with tariffs and the relative stringency indices. Since the relative stringency indices vary by dyad-product-year, standard errors are also clustered at that level.

\section{$<$ Insert Table 3 here $>$}

These results suggest that MRL heterogeneity decreases the probability of having positive trade when the importer is stricter than the exporter implying compliance costs imposed on

\footnotetext{
${ }^{22}$ We got qualitatively similar results by interacting the common religion variable with fixed effects computed at the HS-6 digit level. These results are available upon request.

${ }^{23} \eta(\hat{\rho})=\frac{\phi(\hat{\rho})}{\Phi(\hat{\rho})}$, where $\phi(\cdot)$ and $\Phi(\cdot)$ are the standard normal density function and the standard normal cumulative function, respectively and $\rho_{i j p t}$ are the predicted probabilities from the selection equation.

${ }^{24}$ Following (Helpman et al., 2008), we do not use the normality assumption to recover $\eta_{i j p t}$ and $z_{i j p t}$ from the selection equation and instead work directly with the predicted probabilities, $\rho_{i j p t}$

${ }^{25}$ reg2hdfe in STATA
} 
exporters - the coefficient on $S_{i j p t}^{M}$ is negative and statistically significant in columns (1), (3) and (5). A similar negative effect is observed at the intensive margin in columns (2), (4) and (6). This result is consistent with existing literature (Achterbosch et al., 2009; Burnquist et al., 2011; Drogué and DeMaria, 2012; Ferro et al., 2015).

The coefficient on $S_{i j p t}^{X}$ is found to be negative and statistically significant, especially at the extensive margin of trade in the results reported in columns (1), (3) and (5), and at the intensive margin in column (6). Thus, greater difference of MRLs between trading partners when the exporters have to comply with stricter regulations in their domestic market is found to diminish at least the probability of trading conclusively, if not the value of trade. Thus, contrary to some findings in the existing literature (Blind and Jungmittag, 2005; Xiong and Beghin, 2013) relative stringency in exporter market is also negatively correlated with trade in these results.

These results seem to suggest that irrespective of who imposes them, stricter standards impede trade. Thus, the trade cost effect of stricter standards prevails over the demandenhancing effect without fully accounting for endogeneity in the standards-trade relationship and the results are found to be robust across the three samples. In unreported anaylses, these findings were also found to be robust to replacing tariffs with membership of preferential trade agreements $\left(P T A_{i j t}\right)^{26}$.

The coefficients on the gravity control variables are also consistent with existing gravity estimates. Countries with a common language or membership of a trade accord or which are adjacent to each other have higher probabilities of trading with each other and also trade larger values. Distance is found to reduce both the probability of trading and the value of trade between partners. We also find higher tariffs to reduce trade, both at the intensive and extensive margins, which is an expected result.

The exclusion variable, $E V_{i j p t}$, in the selection equation, and the sample selection, $\eta_{i j p t}$, and firm heterogeneity $z_{i j p t}$ terms in the outcome equation, are also found to be statistically significant in these results. This confirms that countries are self-selected to trade and that firm heterogeneity matters.

\subsection{RGFD estimates: endogeneity matters}

The results reported in Table 3 do not fully account for endogeneity in the standards-trade relationship. We thus use the panel data models described in Baier et al. (2014), specifically

\footnotetext{
${ }^{26}$ These results are available upon request.
} 
the preferred RGFD model with three-way fixed effects to account for this endogeneity. The results from the RGFD estimations are reported in Table 4 for all three samples. All estimations include bilateral pairwise and time-varying importer-product and exporter-product fixed effects, with the product again defined at the HS-4 digit level in the construction of the fixed effects. Standard errors are clustered by dyad-product-year.

\section{$<$ Insert Table 4 here $>$}

The RGFD estimates reported in columns (1) and (3), for samples 1 and 3, respectively, suggest that growth in relative MRL stringency is positively correlated with growth rates of trade, irrespective of the source of stringency. Thus accounting for endogeneity reverses the direction of the estimated trade effects compared to the results reported in Table 3, which is a significant departure from the findings in the existing literature. In particular, results reported for the more complete sample in column (3) of Table 4 suggest that unit additional growth in relative importer stringency is associated with a $46.9 \%$ rise in the growth rate of exports while unit additional growth in relative exporter stringency is associated with a $72.3 \%$ rise in the growth rate of exports, ceteris paribus and on average.

Thus, once we fully account for endogeneity in the standards-trade relationship using threeway fixed effects, the demand enhancing effect of stricter standards prevails over the trade cost effect, irrespective of the source of imposition. The findings in this sub-section are robust to using alternative samples (1 and 3), to substituting tariffs with membership of PTAs $^{27}$ in the estimating equation and to differencing over two, three and four years (the latter results are available upon request).

\subsection{Sensitivity analyses}

\subsubsection{Exogeneity test}

Consistent with the RGFD estimates, endogeneity in the standards-trade relationship suggests that trade may increase in anticipation of a stricter importing or exporting country standard. However a simple exogeneity test requires that any leading of trade before the imposition of stricter standards needs to be well in advance of the estimated trade effects, needs to be economically small, and needs to diminish as the date of imposition of the stricter standard approaches (Baier et al., 2014).

\footnotetext{
${ }^{27}$ Note that the use of three-way fixed effects also accounts for endogeneity in the tariff-trade and PTAtrade relationships in estimation.
} 
Consistent with the analyses in Baier and Bergstrand (2007) and Baier et al. (2014) and as suggested in Wooldridge (2010), we therefore re-estimated the RGFD model to include up to five-year leads of the heterogeneity indices and tariff variables. Results from these analyses, reported in Table 5, indicate statistically insignificant impacts of the leads of the heterogeneity indices on trade. These findings confirm the absence of any feedback effects from changes in trade to changes in relative MRL stringency, thereby validating the use of the RGFD model to account for endogeneity in the standards-trade relationship.

\section{$<$ Insert Table 5 here $>$}

\subsubsection{Dichotomized explanatory variable}

Existing literature on the dichotomization of explanatory variables (for instance see MacCallum et al., 2002) suggests that splitting the relative MRL stringency index into relative importer and relative exporter stringency indices would lend a downward bias to the magnitude of the esimates besides leading to loss of statistical power, even as it makes interpretation easier and serves one of our research objectives.

We therefore examine the robustness of our "endogeneity" findings to the dichotomization of the relative MRL stringency index by replacing the relative importer and relative exporter stringency indices by the non-dichotomized relative MRL stringency index $R_{i j p t}^{A c h}$ in the estimating equations, where

$$
R_{i j p t}^{A c h}=\frac{1}{K} \sum_{k=1}^{K} r_{i j p k t}
$$

and $r_{i j p k t}$ is as defined in equation (1). For the robustness of our "endogeneity" findings, we would expect the coefficient of $R_{i j p t}^{A c h}$ to be negative in the Heckman estimations and positive in the RGFD estimations. Assuringly this is what we find: without fully accounting for endogeneity in the standards-trade relationship, greater relative MRL stringency is associated with a decline in trade at both margins across the three samples in the results reported in Table 6, columns (1) to (6); however, the direction of the estimated trade effects is reversed across the three samples once we fully account for endogeneity in the results reported in Table 7, columns (1) to (3).

$<$ Insert Tables 6 and 7 here $>$ 


\subsubsection{Alternative heterogeneity index from Winchester et al. (2012)}

In a final robustness check, we examine the sensititvity of our analyses to the use of an alternative regulatory heterogeneity index, the Winchester et al. (2012) index, which is defined, at the pesticide level, as follows:

$$
r_{i j p k t}^{W i n}=\frac{a b s\left(M R L_{i p k t}-M R L_{j p k t}\right)}{\max \left(M R L_{p k t}\right)-\min \left(M R L_{p k t}\right)}
$$

and at the product level, as follows:

$$
R_{i j p t}^{W i n}=\frac{1}{K} \sum_{k=1}^{K} r_{i j p k t}
$$

Again, for our "endogeneity" findings to be robust, we would expect the coefficient of $R_{i j p t}^{W i n}$ to be negative in the Heckman estimations and positive in the RGFD estimations. And this is exactly what we find: without fully accounting for endogeneity in the standards-trade relationship, greater relative MRL stringency is associated with a decline in trade at both margins across the three samples in the results reported in Table 6, columns (7) to (12); however, the direction of the estimated trade effects is reversed across the three samples once we fully account for endogeneity in the results reported in Table 7, columns (4) to (6).

\subsubsection{Relative exporter stringency and implementation}

It is easier to associate relative importer stringency with demand-enhancing effects in the importing country. In contrast, consumers in the importing country may like to be assured that more stringent exporter regulation is actually binding for it to have any demand-enhancing effects. If relative exporter stringency were positively correlated with regulatory capacity, rule of law, governance and implementation, then the positive impact of more stringent exporter regulation on trade may be more tenable given that (i) the enforcement of strict public standards like MRLs requires good governance and well functioning public institutions; and (ii) we expect countries with higher levels of governance to be also more concerned about food safety.

To relate these attributes to higher levels of relative exporter stringency, we use the Worldwide Governance Indicators (WGI, Kaufmann et al., 2011) of the World Bank as proxies for the quality of public institutions. These indicators include stability and effectiveness of the government, the extent of corruption, public violence, and - among others - freedom and democracy. Annex Table 1 provides an overview of all six WGI indicators. 
As shown in Annex Table 2, all six indicators are highly correlated, which renders their simultaneous use inappropriate. We therefore employ principal component analysis (PCA), instead of choosing only one indicator or an arbitrary subset, to reduce the dimension of the WGI data. The PCA reveals that one component explains around $84 \%$ of the variation (see Annex Table 3). This component represents institutional quality in the context of our findings on the impact of relative exporter stringency and is denoted as WGI in Figure 5.

Figure 5 is a scatterplot of $S_{i j p t}^{X}$ against $W G I$ for our panel and shows that relative exporter stringency is positively correlated with the attributes embodied in the WGI, thereby lending further robustness to our findings on the positive trade effects of more stringent exporter regulation.

\section{Conclusion}

Using two measures of MRL heterogeneity in the same estimating equation that, departing from existing literature, also include cases when the exporting country is stricter compared to the importing country, we re-examine the effect that dissimilarity in MRL regulation can have on bilateral trade for a large set of trading partners over 2005-14. In another significant contribution, we also fully account for endogeneity in the standards-trade relationship using three-way fixed effects in line with recent developments in the empirical trade literature (for instance Baier et al., 2014).

Stricter standards have both trade cost and demand enhnacing effects and the overall impact depends on which effect prevails (Xiong and Beghin, 2014). Without fully accounting for endogeneity in the standards-trade relationship, results from the Heckman estimations suggest that the trade cost effect prevails. Accounting fully for endogeneity through the use of the RGFD model with three-way fixed effects, empirical results suggest that the demand enhancing effect prevails. Thus, endogeneity-induced biases are found to underestimate the estimated trade effects in our empirical findings and we also provide an economic rationale of why this may be the case.

In sum, our results show that accounting fully for endogeneity reverses the direction of the estimated trade effects, which is a significant departure from the findings in this literature (Achterbosch et al., 2009; Burnquist et al., 2011; Drogué and DeMaria, 2012; Xiong \& Beghin, 2014; Ferro et al., 2015). Specifically, stricter standards are found to have a positive effect on trade in our results, irrespective of the source of stringency. While the positive trade effect of stricter standards has been documented in this literature (Blind and Jungmittag, 
2005; Xiong and Beghin, 2013; Ishaq et al., 2016), these authors did not account for the endogeneity in the standards-trade relationship.

And this endogeneity clearly matters. If the domestic industry has a comparative advantage in meeting regulation and exports are destined for markets where consumer preferences are more pro-food safety, then the demand enhancing effect of more stringent regulation imposed on products more likely to be exported is likely to outweigh the trade cost effect. Similarly, if consumption through imports is sought to be curtailed by the imposition of stricter standards on products where the domestic industry is less competitive (and not because the imported product requires more stringent regulation on scientific or health grounds per se), then the imported product is likely to be more cost-competitive and/or of a better quality than the domestic substitute in the destination market. So, the demand enhancing effect may still outweigh the trade cost effect.

Our results are robust to the choice of different estimation samples (based on dropping assumptions made in the construction of the heterogeneity indices), to using different sets of explanatory variables, to not splitting the regulatory heterogeneity index and to using two altogether different indices.

One shortcoming of this study, like the others that focus only on MRLs, is that it ignores other SPSQ measures that have a bearing on trade in agri-products. It would therefore be useful to examine the results from this research on a broader set of SPSQ measures as well as private standards.

Finally, in the instances where the impact of stricter standards was found to be negative in this study, one should not forget that despite such trade-inhibiting effects, standards are imposed for legitimate reasons such as mitigating health risks from consumption, promoting environmental sustainability and ensuring better working conditions. Thus, a loss in trade may need to be weighed against potential positive external effects of more stringent regulation in a composite measure of welfare. 


\section{References}

Achterbosch, T., Engler, A., Rau, M., and Toledo, R. (2009). Measure the measure: the impact of differences in pesticide mrls on chilean fruit exports to the eu. In International Association of Agricultural Economists Conference, Beijing, China, pages 16-22.

Anderson, J. E. (1979). A theoretical foundation for the gravity equation. The American Economic Review, pages 106-116.

Anderson, J. E. and Van Wincoop, E. (2003). Gravity with gravitas: A solution to the border puzzle. The American Economic Review, 93(1):170-192.

Anderson, J. E. and van Wincoop, E. (2004). Trade costs. Journal of Economic Literature, 42:691-751.

Anderson, J. E. and Yotov, Y. V. (2012). Gold standard gravity. Technical report, National Bureau of Economic Research.

Baier, S. and Bergstrand, J. (2007). Do free trade agreements actually increase members' international trade? Journal of international Economics, 71(1):72-95.

Baier, S., Bergstrand, J., and Feng, M. (2014). Economic integration agreements and the margins of international trade. Journal of International Economics, 93(2):339-350.

Baldwin, R. and Taglioni, D. (2006). Gravity for dummies and dummies for gravity equations. Technical report, National Bureau of Economic Research.

Baldwin, R. E., McLaren, J., and Panagariya, A. (2000). Regulatory protectionism, developing nations, and a two-tier world trade system [with comments and discussion]. In Brookings Trade Forum, pages 237-293. JSTOR.

Beghin, J., Li, Y., and Xiong, B. (2013). The political economy of food standard determination: international evidence from maximum residue limits. Technical report, Working Paper No. 13011.

Blind, K. and Jungmittag, A. (2005). Trade and the impact of innovations and standards: The case of germany and the uk. Applied Economics, 37(12):1385-1398.

Burnquist, H., Shutes, K., Rau, M., de Souza, J., and de Faria, R. (2011). Heterogeneity index of trade and actual heterogeneity index-the case of maximum residue levels (mrls) for pesticides. In Posted presented at the Agricultural and Applied Economics Association?s Annual Meeting, Pittsburgh, PA, pages 24-26. 
Chen, M., Otsuki, T., and Wilson, J. (2006). Do standards matter for export success?, volume 3809. World Bank Publications.

Chen, M. X. and Mattoo, A. (2008). Regionalism in standards: good or bad for trade? Canadian Journal of Economics/Revue canadienne d'économique, 41(3):838-863.

Disdier, A.-C., Fontagné, L., and Mimouni, M. (2008). The impact of regulations on agricultural trade: evidence from the sps and tbt agreements. American Journal of Agricultural Economics, 90(2):336-350.

Drogué, S. and DeMaria, F. (2012). Pesticide residues and trade, the apple of discord? Food Policy, 37(6):641-649.

Engler, A., Nahuelhual, L., Cofré, G., and Barrena, J. (2012). How far from harmonization are sanitary, phytosanitary and quality-related standards? an exporter's perception approach. Food Policy, 37(2):162-170.

Ferro, E., Otsuki, T., and Wilson, J. (2015). The effect of product standards on agricultural exports. Food Policy, 50:68-79.

Fiankor, D., Ehrich, M., and Brümmer, B. (2016). Eu-african regional trade agreements as a development tool to reduce eu border rejections. GlobalFood Discussion Paper $8 \%$.

Ganslandt, M. and Markusen, J. R. (2001). National standards and international trade. Technical report, IUI Working Paper.

Grossman, G. M. and Helpman, E. (1994). Protection for sale. American Economie Review, 84(4):833-850.

Guimarães, P. and Portugal, P. (2010). A simple feasible alternative procedure to estimate models with high-dimensional fixed effects. Stata Journal, 10(4):628-649.

Hansen, H. and Trifković, N. (2014). Food standards are good-for middle-class farmers. World Development, 56:226-242.

Head, K. and Mayer, T. (2013). Gravity equations: Toolkit, cookbook, workhorse. Vol. 4 of Handbook of International Economics.

Helpman, E., Melitz, M., and Rubinstein, Y. (2008). Estimating trade flows: Trading partners and trading volumes. The Quarterly Journal of Economics, 123(2):441-487.

Henson, S. and Jaffee, S. (2008). Understanding developing country strategic responses to the enhancement of food safety standards. The World Economy, 31(4):548-568. 
Ishaq, M., Ping, Q., Haq, Z., Li, C., and Tong, C. (2016). Maximum residue limits and agrifood exports of china: choosing the best estimation technique. Agricultural Economics (Zeme?de?lská Ekonomika), 62(2):78-92.

Jaffee, S. and Henson, S. (2004). Standards and agro-food exports from developing countries: rebalancing the debate, volume 3348. World Bank Publications.

Jongwanich, J. (2009). The impact of food safety standards on processed food exports from developing countries. Food Policy, 34(5):447-457.

Kaufmann, D., Kraay, A., and Mastruzzi, M. (2011). The worldwide governance indicators: methodology and analytical issues. Hague Journal on the Rule of Law, 3(02):220-246.

Lancaster, T. (2000). The incidental parameter problem since 1948. Journal of econometrics, 95(2):391-413.

Lee, J.-W. and Swagel, P. (1997). Trade barriers and trade flows across countries and industries. Review of Economics and Statistics, 79(3):372-382.

Li, Y. (2012). The political economy of food standard determination. international evidence from mrls. Technical report, Mimeo, Iowa State University.

Li, Y. and Beghin, J. (2012). A meta-analysis of estimates of the impact of technical barriers to trade. Journal of Policy Modeling, 34(3):497-511.

Li, Y. and Beghin, J. (2014). Protectionism indices for non-tariff measures: An application to maximum residue levels. Food Policy, 45:57-68.

MacCallum, R., Zhang, S., Preacher, K., and Rucker, D. (2002). On the practice of dichotomization of quantitative variables. Psychological methods, 7(1):19.

Melo, O., Engler, A., Nahuehual, L., Cofre, G., and Barrena, J. (2014). Do sanitary, phytosanitary, and quality-related standards affect international trade? evidence from chilean fruit exports. World Development, 54:350-359.

Nimenya, N., Ndimira, P.-F., and de Frahan, B. H. (2012). Tariff equivalents of nontariff measures: the case of european horticultural and fish imports from african countries. Agricultural Economics, 43(6):635-653.

Otsuki, T., Wilson, J. S., and Sewadeh, M. (2001). Saving two in a billion:: quantifying the trade effect of european food safety standards on african exports. Food policy, 26(5):495514. 
Rodman, D. (2009). How to do xtabond2: An introduction to difference and system gmm in stata. The Stata Journal (2009), 9:86-136.

Silva, J. and Tenreyro, S. (2006). The log of gravity. The Review of Economics and statistics, 88(4):641-658.

Silva, J. and Tenreyro, S. (2010). On the existence of the maximum likelihood estimates in poisson regression. Economics Letters, 107(2):310-312.

Swinnen, J. and Vandemoortele, T. (2011). Trade and the political economy of food standards. Journal of Agricultural Economics, 62(2):259-280.

Trefler, D. (1993). Trade liberalization and the theory of endogenous protection: an econometric study of us import policy. Journal of Political Economy, 101(1):138-160.

Vigani, M., Raimondi, V., and Olper, A. (2010). Gmo regulations, international trade and the imperialism of standards. Technical report, LICOS Discussion Paper.

Wilson, J. S. and Otsuki, T. (2004). Standards and technical regulations and firms in developing countries: new evidence from a world bank technical barriers to trade survey. World Bank, Washington DC.

Winchester, N., Rau, M., Goetz, C., Larue, B., Otsuki, T., Shutes, K., Wieck, C., Burnquist, H., Pinto de Souza, M., and Nunes de Faria, R. (2012). The impact of regulatory heterogeneity on agri-food trade. The World Economy, 35(8):973-993.

Xiong, B. and Beghin, J. (2013). Stringent maximum residue limits, protectionism, and competitiveness: The cases of the us and canada. In Beghin, J., editor, Frontiers of Economics and Globalization. Emerald Press, Bingley, West Yorkshire, UK.

Xiong, B. and Beghin, J. (2014). Disentangling demand-enhancing and trade-cost effects of maximum residue regulations. Economic Inquiry, 52(3):1190-1203.

Xiong, B. and Chen, S. (2014). Estimating gravity equation models in the presence of sample selection and heteroscedasticity. Applied Economics, 46(24):2993-3003. 
Figure 1: Mean $S_{i j p t}^{M}$ (Sample 1: no missing MRL replacements)

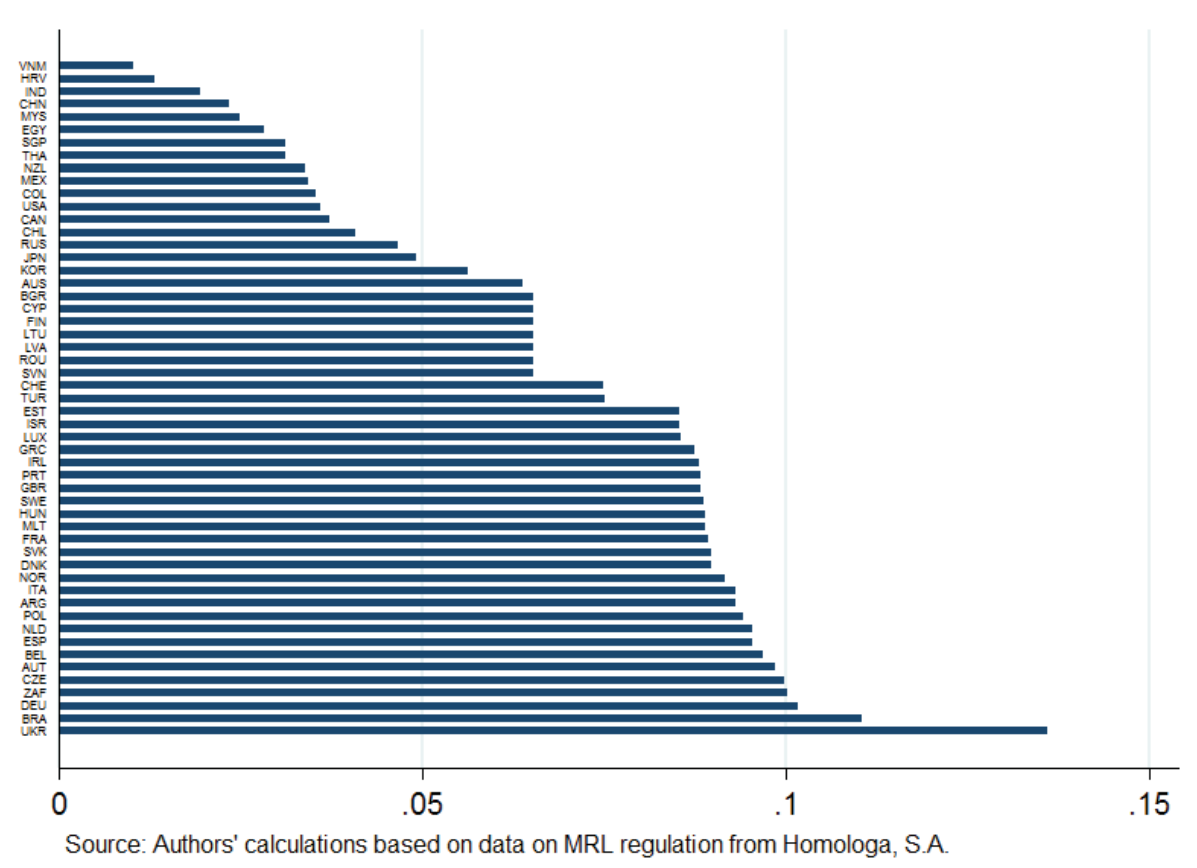

Figure 2: Mean $S_{i j p t}^{X}$ (Sample 1: no missing MRL replacements)

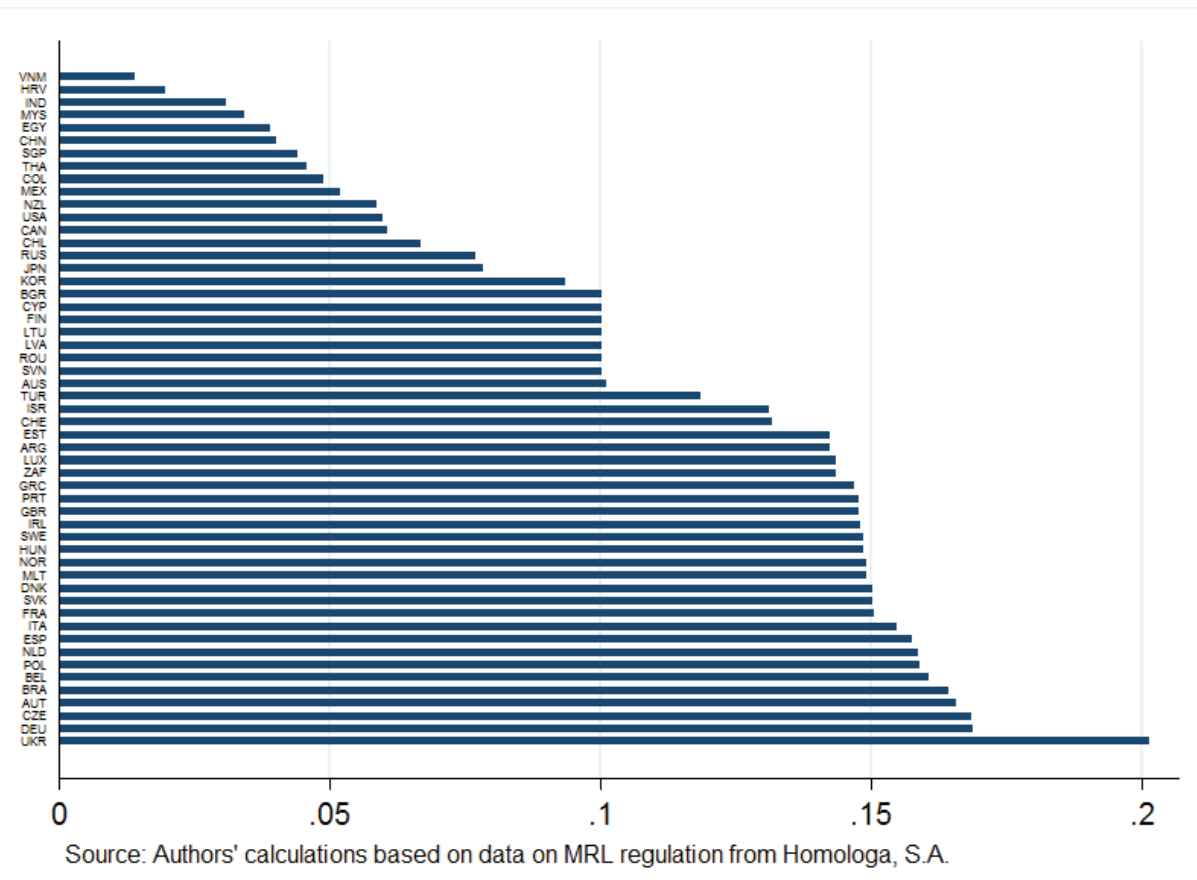


Figure 3: Average number of regulated pesticides per product by country of year 2005 and 2014
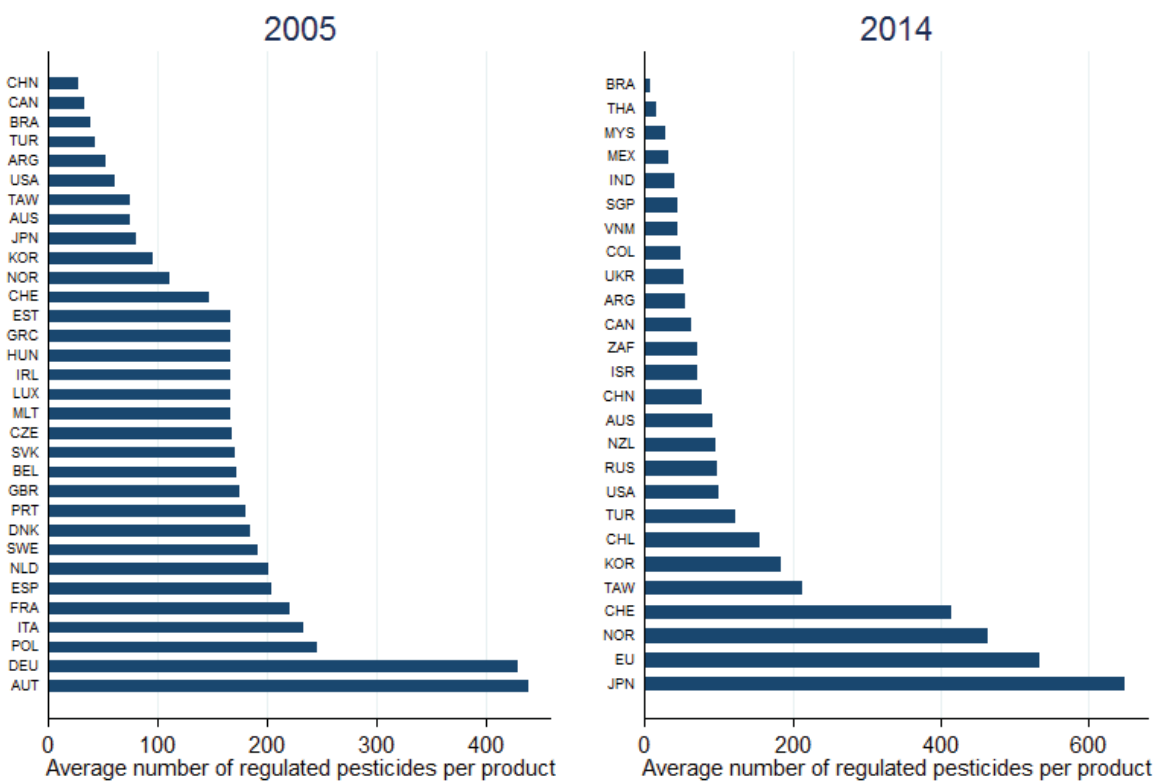

Source: Authors' calculations based on data on MRL regulation from Homologa, S.A.

Figure 4: Average number of regulated products by country of year 2005 and 2014
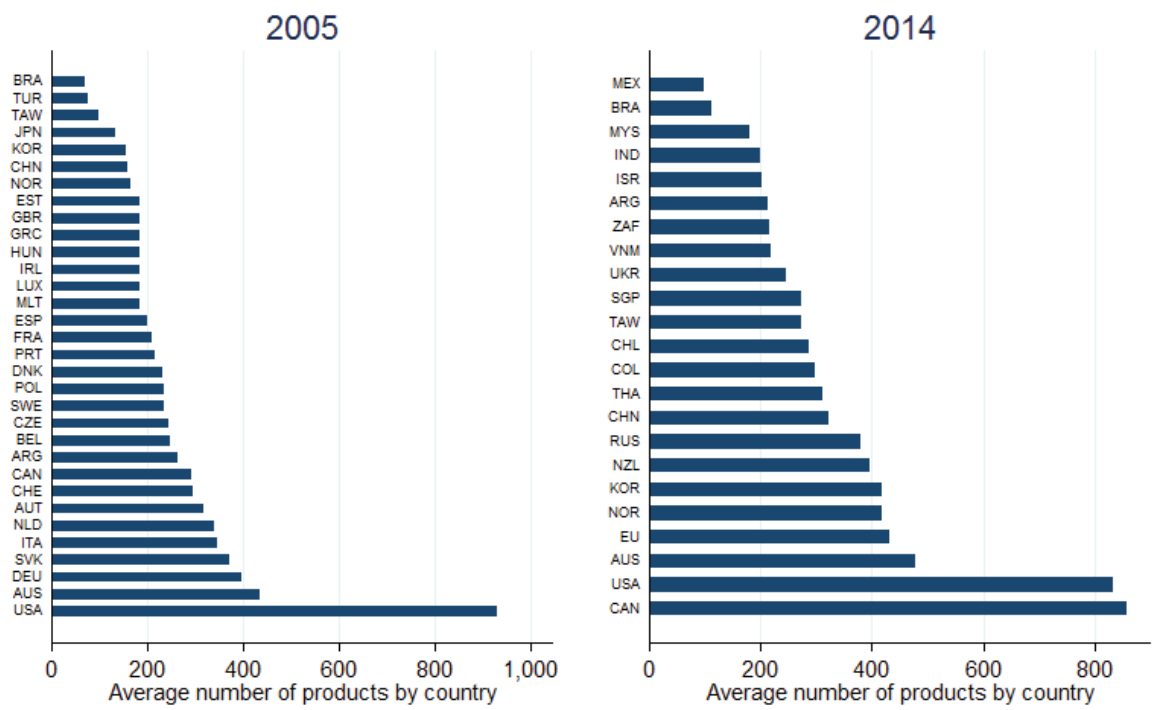

Source: Authors' calculations based on data on MRL regulation from Homologa, S.A.

Note: (1) Only products with Harmonized System concordance included in this paper.

(2) From 2009, all EU member states have harmonized MRL regulation

they thus appear as one observation in the right panel. 
Re-estimating the effects of stricter standards on trade: endogeneity matters

Figure 5: Relative exporter stringency is positively correlated with institutional quality

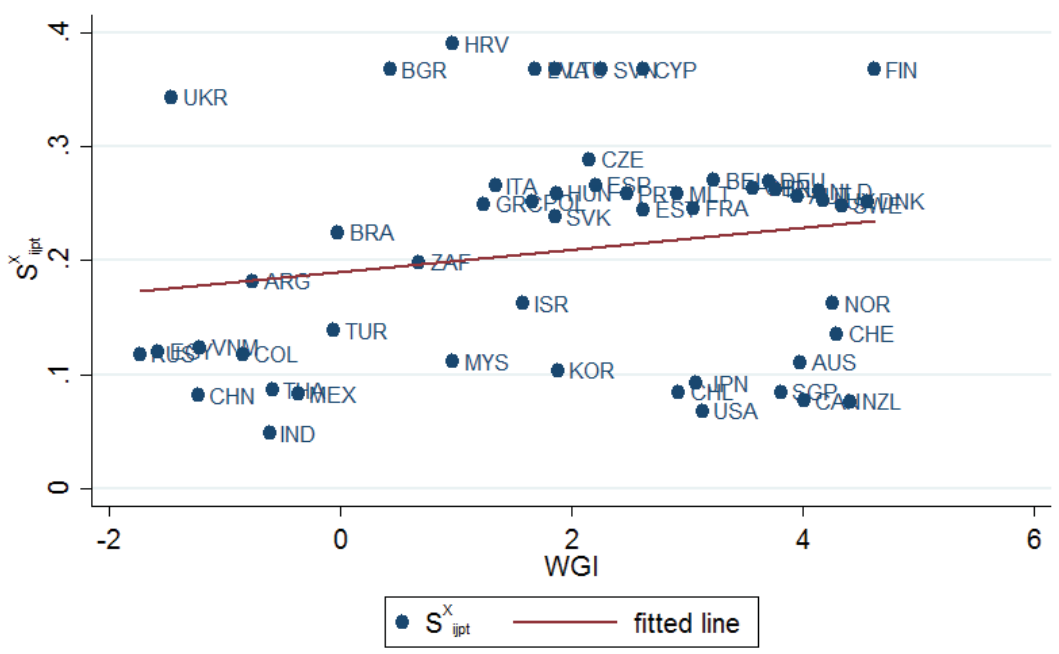

Source: Homologa and World Bank, own graph

Figure 5 plots the correlation between relative exporter stringency and institutional quality

embodied in the World Bank's Worldwide Governance Indicators for our panel. The six WG

indicators are comprised into one WGI variable using principal components analysis. 
Table 1: Many countries use Codex MRLs as default values if national regulation is missing

\begin{tabular}{lll}
\hline \hline Country & First default & Second default \\
\hline Argentina & Codex & 0.01 \\
Australia & 0.01 & \\
Brazil & Codex & \\
Canada & 0.01 & \\
Chile & Codex & \\
China & Codex & \\
Colombia & & \\
Egypt & Codex & \\
European Union & 0.01 & \\
India & Codex & \\
Israel & Codex & \\
Japan & 0.01 & \\
Korea & Codex & \\
Malaysia & Codex & 0.01 \\
Mexico & Codex & \\
New Zealand & 0.01 & \\
Norway & 0.01 & \\
Russia & Codex & \\
Singapore & Codex & \\
South Africa & Codex & 0.01 \\
Switzerland & EU & 0.01 \\
Thailand & Codex & \\
Turkey & Codex & \\
Ukraine & Codex & \\
USA & 0.01 & \\
Vietnam & Codex & \\
\hline \hline
\end{tabular}

Note: Default MRL information from mrldatabase.com (US FDA) except otherwise stated. 
Table 2: Descriptive statistics

\begin{tabular}{|c|c|c|c|c|c|c|c|c|c|}
\hline \multirow[b]{2}{*}{ Variable } & \multicolumn{3}{|c|}{ Sample 1} & \multicolumn{3}{|c|}{ Sample 2} & \multicolumn{3}{|c|}{ Sample 3} \\
\hline & Obs & Mean & Std. Dev. & Obs & Mean & Std. Dev. & Obs & Mean & Std. Dev. \\
\hline$R_{i j p t}$ & 480564 & .336 & .285 & 660666 & .345 & .296 & 807710 & .346 & .272 \\
\hline$S_{i j p t}^{M}$ & 569172 & .099 & .163 & 704112 & .137 & .201 & 808271 & .17 & .219 \\
\hline$S_{i j p t}^{X}$ & 580154 & .112 & .179 & 731634 & .137 & .203 & 811850 & .17 & .219 \\
\hline Imports (USD '000s) & 580154 & 427.7 & 6015.2 & 731634 & 397.5 & 6093.3 & 811850 & 375.7 & 5886.5 \\
\hline Exports (USD '000s) & 580154 & 405.3 & 5782.8 & 731634 & 373.8 & 5589.8 & 811850 & 359.2 & 5651.3 \\
\hline Trade (USD '000s) & 580154 & 416.5 & 4246.4 & 731634 & 385.7 & 4209.3 & 811850 & 367.5 & 4149.6 \\
\hline Distance $(\mathrm{km})$ & 580154 & 6166.2 & 5049.8 & 731634 & 6155.6 & 5039.6 & 811850 & 6220.8 & 5010.4 \\
\hline Contiguity & 580154 & .049 & .217 & 731634 & .049 & .215 & 811850 & .048 & .214 \\
\hline Common language & 580154 & .073 & .260 & 731634 & .069 & .253 & 811850 & .0673499 & .2506271 \\
\hline Common colony & 580154 & .032 & .177 & 731634 & .031 & .175 & 811850 & .031 & .173 \\
\hline PTA membership & 580154 & .519 & .5 & 731634 & .52 & .5 & 811850 & .501 & .5 \\
\hline Common religion & 580154 & .166 & .372 & 731634 & .158 & .364 & 811850 & .158 & .364 \\
\hline Tariffs (simple avg. appd., \%) & 580154 & 1.066 & .224 & 731634 & 1.062 & .212 & 811850 & 1.065 & .206 \\
\hline Share of zero trade & $75 \%$ & & & $76 \%$ & & & $77 \%$ & & \\
\hline Correlation between $S^{M}, S^{X}$ & -0.13 & & & -0.04 & & & -0.13 & & \\
\hline
\end{tabular}

Source of variables: Imports, Exports, Trade (UN Comtrade); $R_{i j p t}, S_{i j p t}^{M}, S_{i j p t}^{X}$ (Homologa); Tariffs (ITC); Distance, Contiguity, Common language, Common colony (CEPII, Head et al. 2010); Common religion (Helpman et al. 2008); PTA membership (De Souza). Sample 1 (S1) only includes observations where the importer and the exporter had an explicit MRL.

Sample $2(\mathrm{~S} 2)=\mathrm{S} 1+$ use of default MRLs to replace missing MRLs.

Sample $3(\mathrm{~S} 3)=\mathrm{S} 2+$ use of sample maxima to replace those missing MRLs which also lacked a default MRL. 
Table 3: Heckman results without endogeneity: irrespective of who imposes them, stricter standards impede trade

\begin{tabular}{|c|c|c|c|c|c|c|}
\hline & \multicolumn{2}{|c|}{ Sample 1} & \multicolumn{2}{|c|}{ Sample 2} & \multicolumn{2}{|c|}{ Sample 3} \\
\hline & $\begin{array}{c}(1) \\
\operatorname{Pr}\left(X_{i j p t}>0\right)\end{array}$ & $\begin{array}{c}(2) \\
\ln \left(X_{i j p t}\right)\end{array}$ & $\begin{array}{c}(3) \\
\operatorname{Pr}\left(X_{i j p t}>0\right)\end{array}$ & $\begin{array}{c}(4) \\
\ln \left(X_{i j p t}\right)\end{array}$ & $\begin{array}{c}(5) \\
\operatorname{Pr}\left(X_{i j p t}>\mathbf{0}\right)\end{array}$ & $\begin{array}{c}(6) \\
\ln \left(X_{i j p t}\right)\end{array}$ \\
\hline$S_{i j p t}^{M}$ & $\begin{array}{c}-0.183^{* * *} \\
(0.00619)\end{array}$ & $\begin{array}{c}-2.716^{* * *} \\
(0.359)\end{array}$ & $\begin{array}{c}-0.128^{* * *} \\
(0.00449)\end{array}$ & $\begin{array}{c}-1.668^{* * *} \\
(0.347)\end{array}$ & $\begin{array}{c}-0.130^{* * *} \\
(0.00386)\end{array}$ & $\begin{array}{c}-1.519^{* * * *} \\
(0.320)\end{array}$ \\
\hline$S_{i j p t}^{X}$ & $\begin{array}{l}-0.189^{* * * *} \\
(0.00522)\end{array}$ & $\begin{array}{l}-0.348 \\
(0.398)\end{array}$ & $\begin{array}{l}-0.118^{* * * *} \\
(0.00431)\end{array}$ & $\begin{array}{l}-0.385 \\
(0.301)\end{array}$ & $\begin{array}{l}-0.107^{* * * *} \\
(0.00379)\end{array}$ & $\begin{array}{c}-0.689^{* *} \\
(0.282)\end{array}$ \\
\hline $\ln \left(1+\tau_{i j p t}\right)$ & $\begin{array}{c}-0.0995^{* * *} \\
(0.00722)\end{array}$ & $\begin{array}{c}-1.396^{* * *} \\
(0.444)\end{array}$ & $\begin{array}{c}-0.0966^{* * *} \\
(0.00672)\end{array}$ & $\begin{array}{c}-1.865^{* * *} \\
(0.443)\end{array}$ & $\begin{array}{c}-0.0946^{* * *} \\
(0.00651)\end{array}$ & $\begin{array}{c}-1.761^{* * *} \\
(0.439)\end{array}$ \\
\hline $\ln \left(\right.$ Dist $\left._{i j}\right)$ & $\begin{array}{l}-0.102^{* * *} \\
(0.00129)\end{array}$ & $\begin{array}{c}-0.550^{* * *} \\
(0.0843)\end{array}$ & $\begin{array}{l}-0.108^{* * *} \\
(0.00114)\end{array}$ & $\begin{array}{c}-0.728^{* * *} \\
(0.0852)\end{array}$ & $\begin{array}{l}-0.105^{* * *} \\
(0.00102)\end{array}$ & $\begin{array}{c}-0.754^{* * *} \\
(0.0834)\end{array}$ \\
\hline Contig $_{i j}$ & $\begin{array}{l}0.157^{* * *} \\
(0.00369)\end{array}$ & $\begin{array}{c}0.959^{* * *} \\
(0.137)\end{array}$ & $\begin{array}{l}0.163^{* * *} \\
(0.00336)\end{array}$ & $\begin{array}{c}1.050^{* * * *} \\
(0.136)\end{array}$ & $\begin{array}{l}0.147^{* * *} \\
(0.00320)\end{array}$ & $\begin{array}{c}1.103^{* * *} \\
(0.123)\end{array}$ \\
\hline Colony $_{i j}$ & $\begin{array}{c}0.0284^{* * * *} \\
(0.00419)\end{array}$ & $\begin{array}{c}-0.233^{* * *} \\
(0.0579)\end{array}$ & $\begin{array}{c}0.0250 * * * \\
(0.00386)\end{array}$ & $\begin{array}{c}-0.161^{* * *} * \\
(0.0528)\end{array}$ & $\begin{array}{c}0.0187 * * * \\
(0.00370)\end{array}$ & $\begin{array}{c}-0.174 * * * \\
(0.0508)\end{array}$ \\
\hline ComLang $_{i j}$ & $\begin{array}{l}0.0699 * * * \\
(0.00283)\end{array}$ & $\begin{array}{c}0.643^{* * *} \\
(0.0757)\end{array}$ & $\begin{array}{c}0.0625^{* * *} \\
(0.00263)\end{array}$ & $\begin{array}{l}0.699 * * * \\
(0.0669)\end{array}$ & $\begin{array}{l}0.0682^{* * *} \\
(0.00249)\end{array}$ & $\begin{array}{l}0.704^{* * *} \\
(0.0702)\end{array}$ \\
\hline$E V_{i j p t}$ & $\begin{array}{c}0.00557^{* * *} \\
(0.000310)\end{array}$ & & $\begin{array}{c}0.00490^{* * *} \\
(0.000274)\end{array}$ & & $\begin{array}{c}0.00494^{* * *} \\
(0.000254)\end{array}$ & \\
\hline$\eta_{i j p t}$ & & $\begin{array}{c}744.3^{* * *} \\
(209.2)\end{array}$ & & $\begin{array}{c}732.4^{* * *} \\
(174.6)\end{array}$ & & $\begin{array}{c}519.8^{* * *} \\
(195.0)\end{array}$ \\
\hline$z_{i j p t}$ & & $\begin{array}{c}12,355^{* * *} \\
(3,833)\end{array}$ & & $\begin{array}{c}12,209 * * * \\
(3,277)\end{array}$ & & $\begin{array}{c}8,175^{* *} \\
(3,639)\end{array}$ \\
\hline$z_{i j p t}^{2}$ & & $\begin{array}{c}-12,782^{* * *} \\
(4,231)\end{array}$ & & $\begin{array}{c}-12,637^{* * *} \\
(3,663)\end{array}$ & & $\begin{array}{c}-8,121^{* *} \\
(4,055)\end{array}$ \\
\hline$z_{i j p t}^{3}$ & & $\begin{array}{c}4,911^{* * *} \\
(1,753)\end{array}$ & & $\begin{array}{c}4,847^{* * *} \\
(1,537)\end{array}$ & & $\begin{array}{l}2,953^{*} \\
(1,697)\end{array}$ \\
\hline $\mathbf{N}$ & 569,172 & 34,606 & 704,112 & 40,801 & 808,271 & 42,018 \\
\hline r2 & 0.395 & 0.677 & 0.388 & 0.681 & 0.375 & 0.680 \\
\hline $\begin{array}{l}\text { Method } \\
\text { Fixed effects }\end{array}$ & $\begin{array}{c}\text { LPM (2wfe) } \\
\text { ipt, jpt }\end{array}$ & $\begin{array}{c}\text { OLS }(2 w f e) \\
\text { ipt, jpt }\end{array}$ & $\begin{array}{c}\text { LPM (2wfe) } \\
\text { ipt, jpt }\end{array}$ & $\begin{array}{c}\text { OLS (2wfe) } \\
\text { ipt, jpt }\end{array}$ & $\begin{array}{c}\text { LPM (2wfe) } \\
\text { ipt, jpt }\end{array}$ & $\begin{array}{c}\text { OLS (2wfe) } \\
\text { ipt, jpt }\end{array}$ \\
\hline
\end{tabular}

Sample 1 only includes observations where the importer and the exporter had an explicit MRL.

Sample $2=$ Sample $1+$ use of default MRLs to replace missing MRLs.

Sample 3 = Sample $2+$ use of sample maxima to replace those missing MRLs which also lacked a default MRL.

The exclusion variable used in the selection equation is a dummy variable for common religion interacted with HS-4 product fixed effects.

Product dimension in the fixed effects is at the HS-4 digit level.

LPM = Linear Probability Model.

Robust standard errors, clustered by dyad-product-year, included in parentheses.

Levels of signicance: ${ }^{*} \mathrm{p}<0.1{ }^{* *} \mathrm{p}<0.05^{* * *} \mathrm{p}<0.01$ 
Table 4: RGFD results, endogeneity matters: irrespective of who imposes them, stricter standards facilitate trade

\begin{tabular}{lccc}
\hline \hline & Sample 1 & Sample 2 & Sample 3 \\
\hline & $(\mathbf{1})$ & $\mathbf{( 2 )}$ & $\mathbf{( 3 )}$ \\
& $d . \ln \left(X_{i j p t}\right)$ & $d . \ln \left(X_{i j p t}\right)$ & $d . \ln \left(X_{i j p t}\right)$ \\
\hline$d . S_{i j p t}^{M}$ & $0.952^{* * *}$ & 0.295 & $0.469^{* * *}$ \\
& $(0.345)$ & $(0.200)$ & $(0.142)$ \\
$d . S_{i j p t}^{X}$ & $1.145^{* * *}$ & 0.323 & $0.723^{* * *}$ \\
& $(0.347)$ & $(0.200)$ & $(0.128)$ \\
$d . \ln \left(1+\tau_{i j p t}\right)$ & $-1.701^{* * *}$ & -0.461 & -0.322 \\
& $(0.638)$ & $(0.749)$ & $(0.760)$ \\
\hline $\mathbf{N}$ & 22,669 & 27,251 & 27,950 \\
r2 & 0.072 & 0.054 & 0.054 \\
\hline Method & RGFD & RGFD & RGFD \\
Fixed effects & d.ipt, d.jpt, ij & d.ipt, d.jpt, ij & d.ipt, d.jpt, ij \\
\hline \hline
\end{tabular}

Sample 1 only includes observations where the importer and the exporter had an explicit MRL.

Sample $2=$ Sample $1+$ use of default MRLs to replace missing MRLs. Sample $3=$ Sample $2+$ use of sample maxima to replace those missing MRLs which also lacked a default MRL.

$\mathrm{d}$ is the first difference operator.

Product dimension in the fixed effects is at the HS-4 digit level.

Robust standard errors, clustered by dyad-product-year, included in parentheses.

Levels of signicance: ${ }^{*} \mathrm{p}<0.1{ }^{* *} \mathrm{p}<0.05{ }^{* * *} \mathrm{p}<0.01$ 
Table 5: Exogeneity test of RGFD estimates

\begin{tabular}{|c|c|c|c|}
\hline & Sample 1 & Sample 2 & Sample 3 \\
\hline & $d . \ln \left(X_{i j p t}\right)$ & d.ln $\left(X_{i j p t}\right)$ & $d . \ln \left(X_{i j p t}\right)$ \\
\hline \multirow{2}{*}{$d . S_{i j p t}^{M}$} & 0.087 & $0.771^{* *}$ & $0.891^{* * *}$ \\
\hline & $(0.547)$ & $(0.301)$ & $(0.199)$ \\
\hline \multirow{2}{*}{$d . S_{j p t}^{X}$} & $-0.900^{*}$ & $0.836^{* * *}$ & $0.942^{* * *}$ \\
\hline & $(0.482)$ & $(0.264)$ & $(0.171)$ \\
\hline \multirow{2}{*}{$d . l n\left(1+\tau_{i j p t}\right)$} & $-1.675^{*}$ & $-2.042^{* *}$ & $-1.756^{*}$ \\
\hline & $(0.891)$ & $(0.909)$ & $(0.953)$ \\
\hline \multirow{2}{*}{$S_{i j p t+1}^{M}$} & 0.710 & $1.172^{* *}$ & 0.246 \\
\hline & $(0.828)$ & $(0.578)$ & $(0.301)$ \\
\hline \multirow{2}{*}{$S_{i j p t+1}^{X}$} & 0.759 & 0.758 & $0.572^{*}$ \\
\hline & $(0.671)$ & $(0.552)$ & $(0.297)$ \\
\hline \multirow[t]{2}{*}{$\ln \left(1+\tau_{i j p t+1}\right)$} & 1.152 & 0.585 & 0.677 \\
\hline & $(2.317)$ & $(2.199)$ & $(2.164)$ \\
\hline \multirow{2}{*}{$S_{i j p t+2}^{M}$} & -0.465 & -0.150 & 0.218 \\
\hline & $(1.024)$ & $(0.698)$ & $(0.358)$ \\
\hline \multirow{2}{*}{$S_{i j p t+2}^{X}$} & -0.085 & 0.758 & -0.356 \\
\hline & $(0.788)$ & $(0.719)$ & $(0.354)$ \\
\hline \multirow{2}{*}{$\ln \left(1+\tau_{i j p t+2}\right)$} & 0.257 & 1.340 & 1.132 \\
\hline & $(1.440)$ & $(1.542)$ & $(1.486)$ \\
\hline \multirow{2}{*}{$S_{i j p t+3}^{M}$} & -0.890 & -0.863 & $-1.620 * * *$ \\
\hline & $(2.217)$ & $(0.699)$ & $(0.520)$ \\
\hline \multirow{2}{*}{$S_{i j p t+3}^{X}$} & 0.438 & -0.568 & -0.640 \\
\hline & $(1.771)$ & $(0.647)$ & $(0.433)$ \\
\hline \multirow[t]{2}{*}{$\ln \left(1+\tau_{i j p t+3}\right)$} & -1.179 & 0.434 & 0.895 \\
\hline & $(1.799)$ & $(1.821)$ & $(1.808)$ \\
\hline \multirow{2}{*}{$S_{i j p t+4}^{M}$} & 1.120 & 0.610 & 0.688 \\
\hline & $(2.321)$ & $(0.497)$ & $(0.438)$ \\
\hline \multirow[t]{2}{*}{$S_{i j p t+4}^{X}$} & -2.045 & -0.812 & -0.157 \\
\hline & $(1.851)$ & $(0.555)$ & $(0.364)$ \\
\hline \multirow[t]{2}{*}{$\ln \left(1+\tau_{i j p t+4}\right)$} & -0.598 & -2.897 & -2.707 \\
\hline & $(2.936)$ & $(1.789)$ & $(1.804)$ \\
\hline \multirow[t]{2}{*}{$S_{i j p t+5}^{M}$} & -0.184 & 0.467 & $0.656^{*}$ \\
\hline & $(1.539)$ & $(0.441)$ & $(0.366)$ \\
\hline \multirow[t]{2}{*}{$S_{i j p t+5}^{X}$} & $2.301^{* *}$ & $1.157^{* *}$ & $0.868^{* * *}$ \\
\hline & $(1.108)$ & $(0.523)$ & $(0.330)$ \\
\hline \multirow[t]{2}{*}{$\ln \left(1+\tau_{i j p t+5}\right)$} & 0.676 & 1.607 & 1.252 \\
\hline & $(1.937)$ & $(1.715)$ & $(1.656)$ \\
\hline $\mathbf{N}$ & 7100 & 11019 & 11549 \\
\hline r2 & 0.145 & 0.109 & 0.114 \\
\hline Method & RGFD & RGFD & RGFD \\
\hline Fixed effects & d.ipt, d.jpt, ij & d.ipt, d.jpt, ij & d.ipt, d.jpt, ij \\
\hline
\end{tabular}

Sample 1 only includes observations where the importer and the exporter had an explicit MRL.

Sample $2=$ Sample $1+$ use of default MRLs to replace missing MRLs.

Sample 3 = Sample $2+$ use of sample maxima to replace those missing MRLs which also lacked a default MRL.

$\mathrm{d}$ is the first difference operator.

Product dimension in the fixed effects is at the HS-4 digit level.

Robust standard errors, clustered by dyad-product-year, included in parentheses. Levels of signicance: ${ }^{*} \mathrm{p}<0.1 * * \mathrm{p}<0.05 * * * \mathrm{p}<0.01$ 


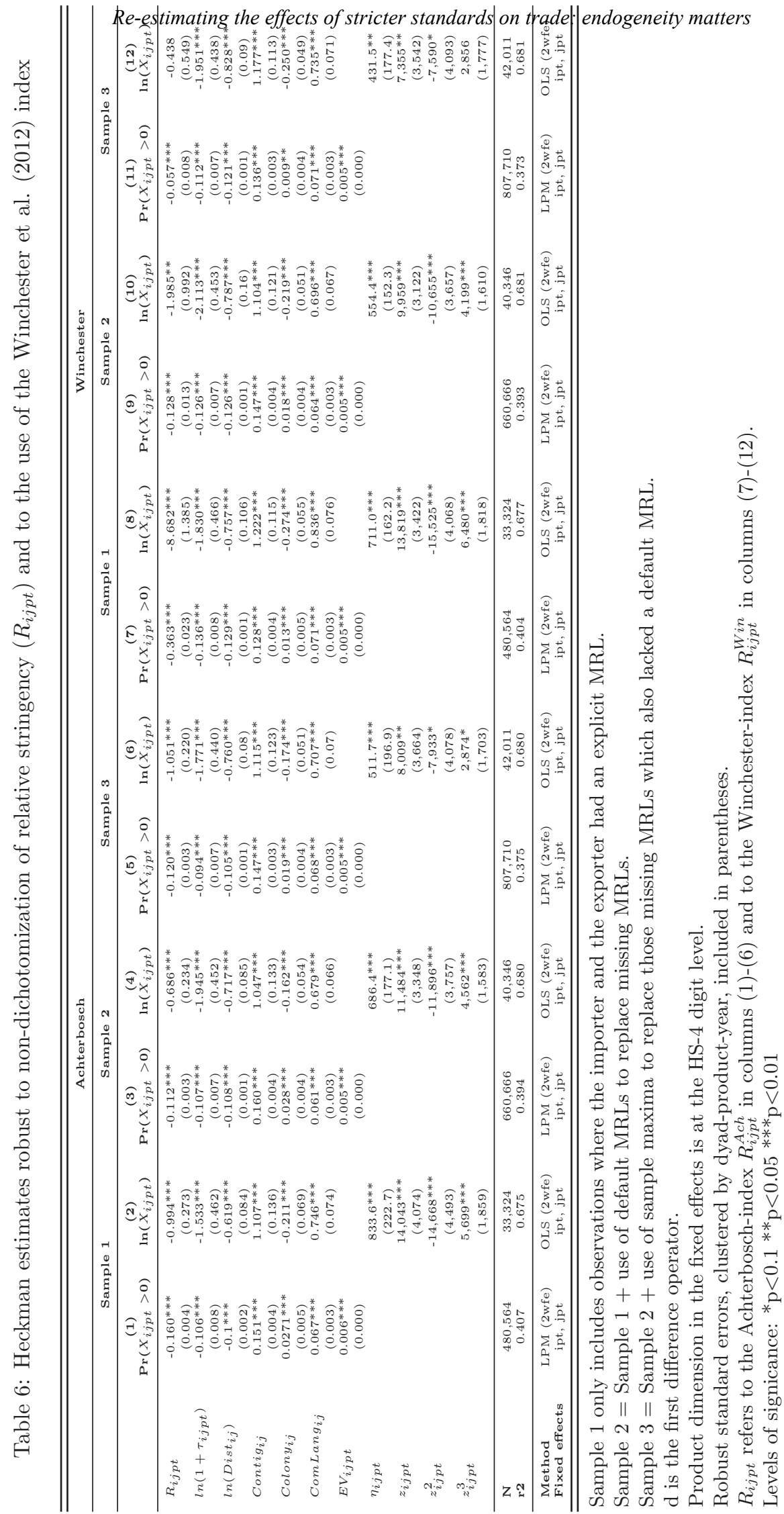


Table 7: RGFD estimates robust to non-dichotomization of relative stringency $\left(R_{i j p t}\right)$ and to the use of the Winchester et al. (2012) index

\begin{tabular}{|c|c|c|c|c|c|c|}
\hline & \multicolumn{3}{|c|}{ Achterbosch } & \multicolumn{3}{|c|}{ Winchester } \\
\hline & Sample 1 & Sample 2 & Sample 3 & Sample 1 & Sample 2 & Sample 3 \\
\hline & (1) & $(2)$ & (3) & (4) & (5) & (6) \\
\hline & d.ln $\left(X_{i j p t}\right)$ & $d . \ln \left(X_{i j p t}\right)$ & $d . \ln \left(X_{i j p t}\right)$ & $d . \ln \left(X_{i j p t}\right)$ & d. $\ln \left(X_{i j p t}\right)$ & $d . \ln \left(X_{i j p t}\right)$ \\
\hline$d . R_{i j p t}$ & $\begin{array}{c}0.788^{* * *} \\
(0.180)\end{array}$ & $\begin{array}{c}0.426^{* * *} \\
(0.148)\end{array}$ & $\begin{array}{c}0.608^{* * *} \\
(0.1000)\end{array}$ & $\begin{array}{c}4.251^{* * *} \\
(1.552)\end{array}$ & $\begin{array}{c}0.467^{*} \\
(0.273)\end{array}$ & $\begin{array}{c}0.157 \\
(0.231)\end{array}$ \\
\hline$d . \ln \left(1+\tau_{i j p t}\right)$ & $\begin{array}{c}-1.784^{* * *} \\
(0.628)\end{array}$ & $\begin{array}{l}-0.803 \\
(0.727)\end{array}$ & $\begin{array}{c}-0.314 \\
(0.761)\end{array}$ & $\begin{array}{c}-1.866^{* * *} \\
(0.657)\end{array}$ & $\begin{array}{c}-0.892 \\
(0.720)\end{array}$ & $\begin{array}{l}-0.531 \\
(0.752)\end{array}$ \\
\hline $\mathbf{N}$ & 22,702 & 27,028 & 27,948 & 21,982 & 27,028 & 27,948 \\
\hline r2 & 0.071 & 0.054 & 0.054 & 0.071 & 0.054 & 0.052 \\
\hline Method & RGFD & RGFD & RGFD & RGFD & RGFD & RGFD \\
\hline Fixed effects & d.ipt, d.jpt, ij & d.ipt, d.jpt, ij & d.ipt, d.jpt, ij & d.ipt, d.jpt, ij & d.ipt, d.jpt, ij & d.ipt, d.jpt, ij \\
\hline
\end{tabular}

Sample 1 only includes observations where the importer and the exporter had an explicit MRL.

Sample $2=$ Sample $1+$ use of default MRLs to replace missing MRLs.

Sample 3 = Sample $2+$ use of sample maxima to replace those missing MRLs which also lacked a default MRL.

$\mathrm{d}$ is the first difference operator.

Product dimension in the fixed effects is at the HS-4 digit level.

Robust standard errors, clustered by dyad-product-year, included in parentheses

$R_{i j p t}$ refers to the Achterbosch-index $R_{i j p t}^{A c h}$ in columns (1)-(3) and to the Winchester-index $R_{i j p t}^{W i n}$ in columns (4)-(6).

Levels of signicance: ${ }^{*} \mathrm{p}<0.1{ }^{* *} \mathrm{p}<0.05{ }^{* * *} \mathrm{p}<0.01$

Table 8: List of included products

\begin{tabular}{llllllll}
\hline \hline HS Code & Product & HS Code & Product & HS Code & Product & HS Code & Product \\
\hline $080211 / 2$ & Almonds & 080920 & Cherries & 080710 & Melons & 080430 & Pineapples \\
080810 & Apples & 080240 & Chestnuts & 100820 & Millet & 080940 & Plums \\
080910 & Apricots & 070320 & Garlic & 071120 & Olives & 081020 & Raspberries \\
070920 & Asparagus & $080221 / 2$ & Hazelnuts & 070310 & Onions & 070970 & Spinach \\
070930 & Aubergine & 081050 & Kiwi & 080510 & Oranges & 081010 & Strawberries \\
080440 & Avocados & 080530 & Lemons & 080720 & Papayas & $080231 / 2$ & Walnuts \\
070410 & Broccoli & 080520 & Mandarins & 080930 & Peaches & 080711 & Watermelons \\
070940 & Celery & 080450 & Mangos & 080820 & Pears & & \\
\hline \hline
\end{tabular}


Annex Table A1: Definition of WGI, Source: Kaufmann, Kraay and Mastruzzi (2011).

\begin{tabular}{ll}
\hline \hline Indicator & Brief Definition \\
\hline (1) Control of corruption & Extent to which public power is exercised for private gain \\
(2) Government effectiveness & Perceptions of the quality of public services \\
(3) Political stability & Likelihood that the government will be destabilised or overthrown \\
(4) Regulatory quality & Ability of the government to formulate and implement sound policies \\
(5) Rule of law & Confidence in enforcement of contracts, property rights \\
(6) Voice and accountability & Participation in government, freedom of expression, association \\
\hline \hline
\end{tabular}

Annex Table A2: Correlation-matrix of WGI

\begin{tabular}{lllllll}
\hline \hline Indicator & CoC & GE & PS & RQ & RoL & VaA \\
\hline Control of corruption (CoC) & 1.000 & & & & & \\
Government effectiveness (GE) & 0.928 & 1.000 & & & & \\
Political stability (PS) & 0.733 & 0.676 & 1.000 & & & \\
Regulatory quality (RQ) & 0.864 & 0.934 & 0.618 & 1.000 & & \\
Rule of law Confidence (RoL) & 0.940 & 0.934 & 0.773 & 0.892 & 1.000 & \\
Voice and accountability (VaA) & 0.776 & 0.765 & 0.676 & 0.778 & 0.816 & 1.000 \\
\hline \hline
\end{tabular}

Annex Table A3: Principal component rotation

\begin{tabular}{lllll}
\hline \hline Component & Eigenvalue & Difference & Proportion & Cumulative \\
\hline Comp1 & 5.054 & 4.608 & 0.842 & 0.842 \\
Comp2 & .446 & .161 & 0.074 & 0.917 \\
Comp3 & .285 & .166 & 0.048 & 0.964 \\
Comp4 & .12 & .0691 & 0.02 & 0.984 \\
Comp5 & .051 & .006 & 0.008 & 0.993 \\
Comp6 & .044 & & 0.007 & 1.0000 \\
\hline \hline
\end{tabular}

Annex Table A4: Principal components (eigenvectors)

\begin{tabular}{lll}
\hline \hline Indicator & Comp1 & Unexplained \\
\hline Control of Corruption & 0.425 & .086 \\
Government Effectiveness & 0.425 & .085 \\
Political Stability & 0.358 & .351 \\
Regulatory Quality & 0.413 & .137 \\
Rule of Law & 0.434 & .048 \\
Voice and Accountabbility & 0.388 & .239 \\
\hline \hline
\end{tabular}

